\title{
Re-engineering organocatalysts for asymmetric Friedel- Crafts alkylation of indoles through computational studies
}

\author{
Gabriela G. Gerosa, Maribel O. Marcarino, Rolando A. Spanevello, Alejandra G. Suarez, and Ariel M. Sarotti
}

J. Org. Chem., Just Accepted Manuscript • DOI: 10.1021/acs.joc.0c01256 • Publication Date (Web): 09 Jul 2020

Downloaded from pubs.acs.org on July 10, 2020

\section{Just Accepted}

"Just Accepted" manuscripts have been peer-reviewed and accepted for publication. They are posted online prior to technical editing, formatting for publication and author proofing. The American Chemical Society provides "Just Accepted" as a service to the research community to expedite the dissemination of scientific material as soon as possible after acceptance. "Just Accepted" manuscripts appear in full in PDF format accompanied by an HTML abstract. "Just Accepted" manuscripts have been fully peer reviewed, but should not be considered the official version of record. They are citable by the Digital Object Identifier (DOI®). "Just Accepted" is an optional service offered to authors. Therefore, the "Just Accepted" Web site may not include all articles that will be published in the journal. After a manuscript is technically edited and formatted, it will be removed from the "Just Accepted" Web site and published as an ASAP article. Note that technical editing may introduce minor changes to the manuscript text and/or graphics which could affect content, and all legal disclaimers and ethical guidelines that apply to the journal pertain. ACS cannot be held responsible for errors or consequences arising from the use of information contained in these "Just Accepted" manuscripts. 


\title{
Re-engineering organocatalysts for asymmetric Friedel-Crafts alkylation of indoles through computational studies
}

Gabriela G. Gerosa, Maribel O. Marcarino, Rolando A. Spanevello, Alejandra G. Suárez, Ariel

\author{
M. Sarotti*
}

Instituto de Química Rosario (CONICET-UNR), Facultad de Ciencias Bioquímicas y

Farmacéuticas, Universidad Nacional de Rosario, Suipacha 531, Rosario 2000, Argentina.

KEYWORDS: rational design, organocatalysis, Friedel-Crafts, ONIOM, DFT, computational screening.

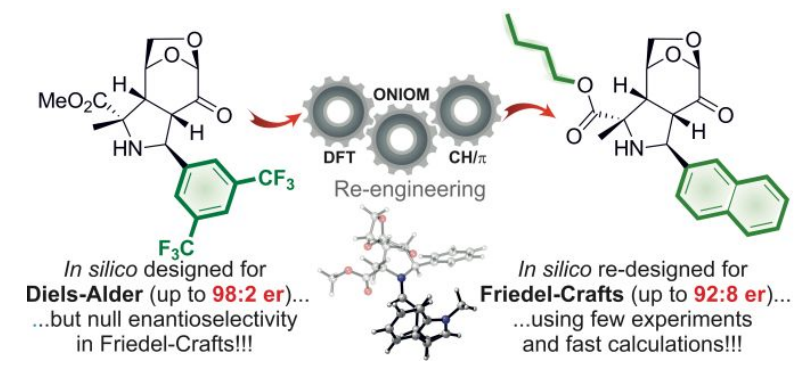

\begin{abstract}
The discovery of efficient organocatalysts is generally carried out by thorough experimental screening of different candidates. We recently reported an efficient organocatalyst for iminium-ion based asymmetric Diels-Alder reactions following a rational design approach. This result encouraged us to test this optimal catalyst in the mechanistically related FriedelCrafts alkylation of indoles, but to our surprise almost null enantioselectivity was observed. The results did not significantly improve with structurally related catalysts, and a totally unexpected facial selectivity inversion was also noticed. Using DFT calculations by modeling the competing transition structures with ONIOM we could unravel the origins of those findings, further employed to predict the most efficient catalyst for this new transformation. The computational results were validated experimentally (up to 92:8 er), providing another successful example of a general strategy to accelerate catalysts development which still remains underexplored.
\end{abstract}




\section{Introduction}

The synthesis of enantiopure molecules remains one of the leading areas of research in organic chemistry. Since the beginning of this century, asymmetric organocatalysis has stood out as a practical strategy to generate optically active compounds using metal-free and mild reaction conditions. ${ }^{1}$ A vast arsenal of articles has been published in this field, with a rich variety of catalysts and activation modes applied over a large set of asymmetric transformations. ${ }^{2}$ The process towards finding an optimal catalyst for a given transformation is typically carried out by trial and error experimentation. Often steric or electronic modifications in the catalyst and/or reagents end up greatly affecting the selectivity and reactivity of the reaction. For instance, many organocatalytic systems are substrate biased, ${ }^{2 \mathrm{~d}}$ or show remarkable differences in mechanistically related transformations (vide infra). This has led to the development of novel experimental methodologies to facilitate the search for broadly efficient catalysts, such as the multisubstrate screening. ${ }^{2 \mathrm{e}}$ Anticipating the effect of the structural variations in the catalyst and/or substrate on the system performance is one of the Holy Grails in catalysis, as this would facilitate the design of efficient inductors for a target transformation. ${ }^{3}$

Modern computational chemistry has become a leading tool to unravel the chemical secrets of interacting systems, hence paving the way to catalyst development. Historically, the impressive predictive power of quantum-based approaches have been focused on understanding the origins of reactivity and selectivity of almost all landmark asymmetric transformations. ${ }^{4}$ Although the value of those studies is beyond question, it is also imperative to recognize the importance of reversing the timeline of the events by incorporating the QM predictions prior the experimental screening, which is the basis of the rational design of catalysts. ${ }^{3}$ One popular approach consists in building QSAR (quantitative structure activity relationship) models by correlating the experimental information available with descriptors resulting from DFT (density functional theory) calculations using regression tools. ${ }^{5}$ A different strategy is based on estimating the selectivity of a process by computing the relative energy of the competing stereocontrolling transition structures. ${ }^{6}$ However, despite the availability of validated methods and increasingly powerful computational resources it is curious the relative 
scarcity of organocatalysts rationally designed from scratch using DFT calculations and further validated experimentally. ${ }^{7}$

As part of our ongoing interest in developing new tools of asymmetric synthesis from levoglucosenone, a biomass derived chiral enone, ${ }^{8}$ we recently reported the rational design of an efficient organocatalyst for the Diels-Alder reaction between $E$ cinnamaldehyde (2) and cyclopentadiene (3), Scheme 1. Using an ONIOM-derived in silico screening pyrrolidine 1a was identified as a hit catalyst, which afforded excellent enantioselectivities (up to $97 \%$ ee) when it was synthesized and evaluated. ${ }^{9}$

Given the promising results obtained in Diels-Alder reactions (DA), we next turned our attention to the Friedel-Crafts (FC) alkylation of indoles, one of the oldest but still useful chemical transformations widely explored in organocatalysis. ${ }^{10}$ The reaction was studied with a large variety of catalysts with results ranging from poor to excellent depending on the catalyst, substrate and reaction conditions. ${ }^{10}$ However, our best catalyst 1a yielded null selectivity when tested in the reaction between 2 and N-methylindole (5), Scheme 1. This finding raised the question whether we could rationally design a new pyrrolidine structurally related to 1a but now efficient for the FC under study.

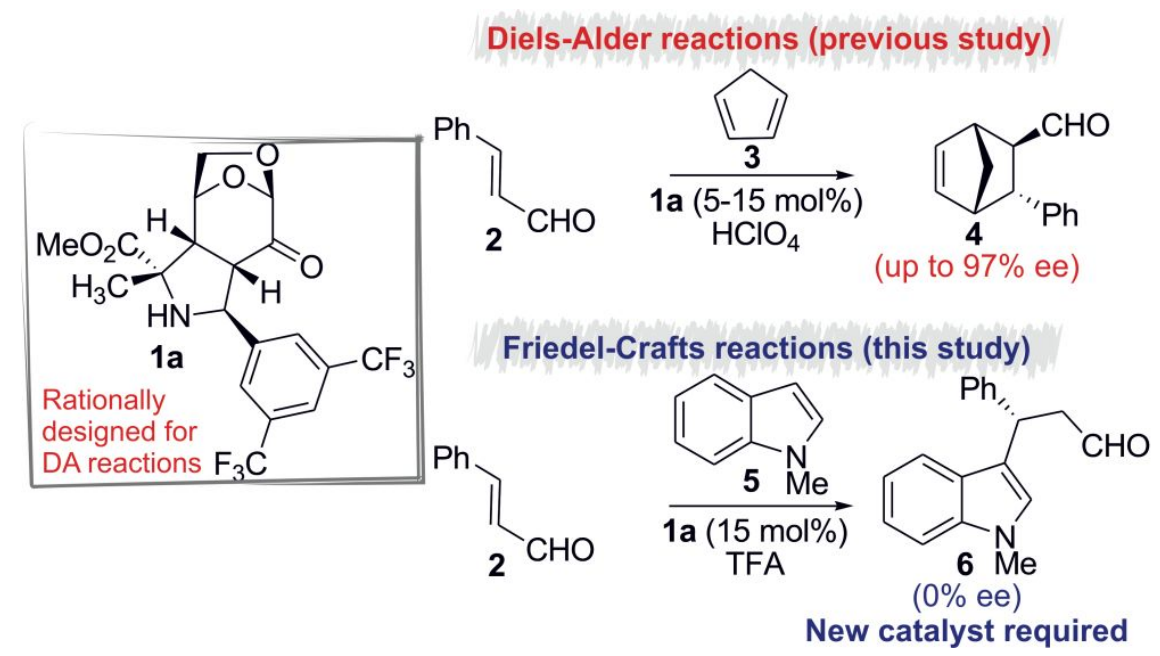

Scheme 1. Performance of catalyst 1a in Diels-Alder and Friedel-Crafts reactions using $(E)$-cinnamaldehyde as electrophile.

\section{Results and discussion}

We started evaluating our optimal catalyst previously found for DA reactions (pyrrolidine 1a, Scheme 1). After preliminary screening of the reaction conditions between $\mathbf{2}$ and $\mathbf{5}$, 
we selected TFA as co-catalyst and a 85:15 mixture of DCM/iPrOH at $0^{\circ} \mathrm{C}$. The alkylation product $\mathbf{6}$ was obtained in excellent yields and low reaction time, but almost none enantiomeric purity ( 50:50 er). Unfortunately, changing the solvent and co-catalyst did not improve the result. The reduction of the enantioselectivity observed when using $\mathrm{N}$-methylindole as the nucleophilic counterpart has been well documented, ${ }^{11}$ yet such dramatic reduction in the selectivity outcome caught our attention. In an effort to unveil the source of the absence of asymmetric induction, we next synthesized and evaluated few analogues of 1a by modulating the nature of the substituted phenyl group at C-7 and the alkyl group at C-8. These modifications could be easily achieved following our previously reported procedure involving a 1,3-dipolar cycloaddition between levoglucosenone (7) and in situ generated azomethine ylides followed by a tandem acidcatalyzed retro-Mannich//Mannich isomerization (Scheme 2). ${ }^{12}$

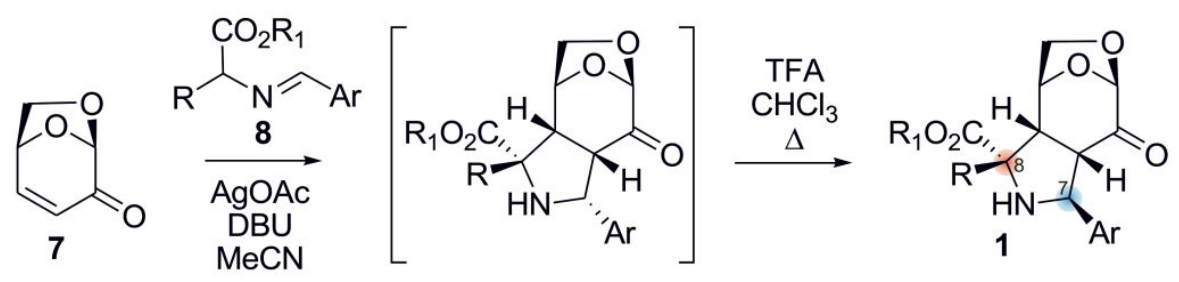

Scheme 2. Synthesis of pyrrolidines $\mathbf{1}$.

The new catalysts were evaluated in the FC reaction under study using the same experimental conditions, and the results are shown in Table 1. 
Table 1. Effect of the pyrrolidine structure on the FC reaction between $\mathbf{2}$ and $\mathbf{5}^{\mathrm{a}}$
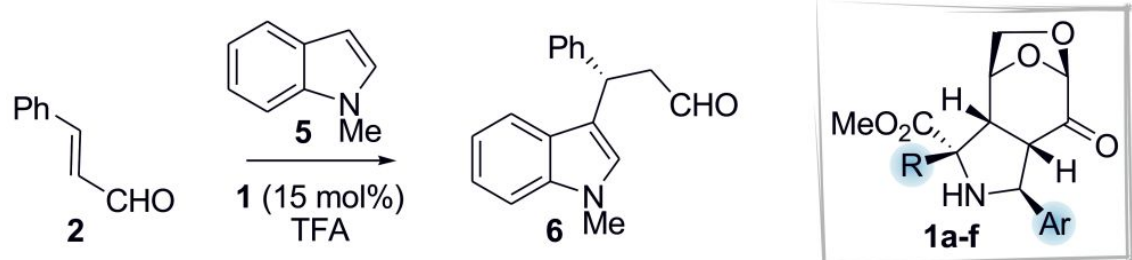

\begin{tabular}{ccccccc}
\hline Entry & Cat & $\mathrm{R}$ & $\mathrm{Ar}$ & $\mathrm{t}(\mathrm{h})$ & ${\text { Yield }(\%)^{\mathrm{b}}}^{\mathrm{er}(S / R)^{\mathrm{c}}}$ \\
\hline 1 & $\mathbf{1 a}$ & $\mathrm{Me}$ & $3,5-\mathrm{CF}_{3}-\mathrm{Ph}$ & 5 & 100 & $50: 50$ \\
2 & $\mathbf{1 b}$ & $\mathrm{Me}$ & $\mathrm{Ph}$ & 2 & 100 & $70: 30$ \\
3 & $\mathbf{1 c}$ & $\mathrm{Bn}$ & $\mathrm{Ph}$ & 18 & 100 & $70: 30$ \\
4 & $\mathbf{1 d}$ & ${ }^{i} \mathrm{Bu}$ & $\mathrm{Ph}$ & 18 & 18 & $53: 47$ \\
5 & $\mathbf{1 e}$ & $\mathrm{Me}$ & $p-\mathrm{OMe}-\mathrm{Ph}$ & 4 & 100 & $67: 33$ \\
6 & $\mathbf{1 f}$ & $\mathrm{Me}$ & $p-\mathrm{NO}_{2}-\mathrm{Ph}$ & 3 & 100 & $53: 47$
\end{tabular}

a General reaction conditions: $5(0.45 \mathrm{mmol}), 2(0.9 \mathrm{mmol}), 15 \mathrm{~mol} \%$ catalyst $(0.07 \mathrm{mmol}), 15 \mathrm{~mol} \% \mathrm{TFA}(0.07 \mathrm{mmol}), \mathrm{DCM} / \mathrm{PPOH}$ $85: 15,0{ }^{\circ} \mathrm{C}$. ${ }^{b}$ Isolated yield after column chromatography. ${ }^{\mathrm{c}}$ Determined by ${ }^{1} \mathrm{H}$ NMR using a modified Mosher procedure.

The facial selectivities ranged from poor to modest (up to 70:30 er). Replacement of the key 3,5- $\mathrm{CF}_{3}-\mathrm{Ph}$ substituent (entry 1) by an undecorated phenyl group (entry 2) proved beneficial. The introduction of electron rich groups (entry 5) hardly changed the results, but electron withdrawing substituents (entry 6) restored the poor enantioselectivity levels. On the other hand, increasing the bulkiness at C-8 (entries 3-4) enlarged the reaction time and in the case of $\mathbf{1 d}$ coupled with a concomitant e.r. reduction. The decrease of selectivity as result of a large steric hindrance at the $\beta$ face of the pyrrolidine (either by introducing a bulky group at C-7 as in 1a or C-8 as in 1d) was in clear contrast to our previous findings in DA cycloadditions. The configurational assignment of the reaction outcome was carried out by a modified Mosher's method ${ }^{13}$ using ( $S$ )-O-Acetyl mandelic acid as chiral derivatizing agent, ${ }^{14}$ and further validated by comparing the optical rotation reported for 6. ${ }^{11 a}$ In all cases the major enantiomer of the organocatalyzed FC reaction featured an $S$ configuration at the newly created stereocenter, revealing a striking reversal of the facial selectivity as well. The condensation of $\mathbf{2}$ with the pyrrolidine $\mathbf{1}$ under acid conditions yields the corresponding iminium ion Im with $(E)$-configuration as unambiguously demonstrated by combination of DFT calculations and NMR spectroscopy (Scheme 3). ${ }^{9}$ 


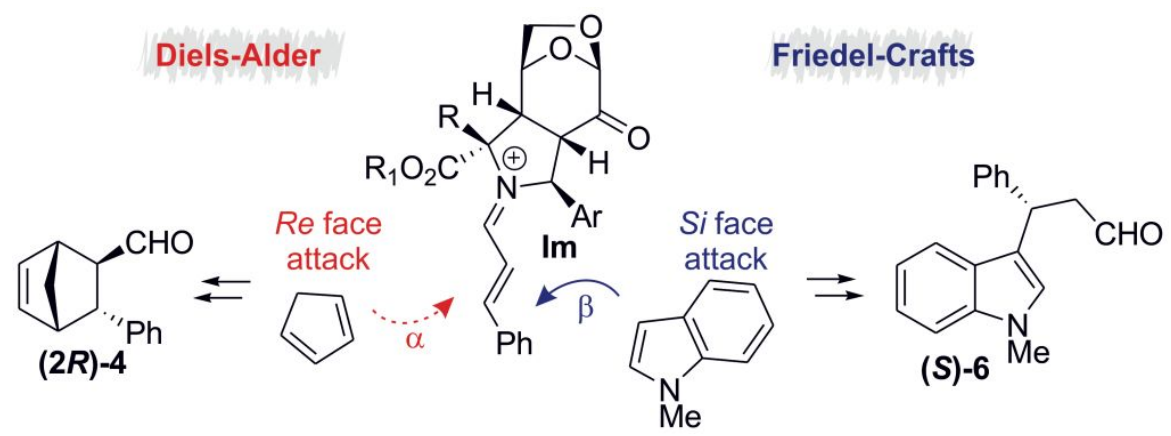

Scheme 3. Facial selectivity observed in organocatalyzed Diels-Alder and Friedel-Crafts reactions using levoglucosenone-derived pyrrolidines.

Assuming that the iminium ion is configurationally well-behaved, the major $(S)-6$ is consistent with the preferred approach of the indole from the $\beta$ face of the electrophile ( $s i$ face attack), contrary to the $r e$ face ${ }^{15}$ addition taking place by switching the nucleophilic counterpart to cyclopentadiene as in the DA reaction., ${ }^{9}$, 2 a The preferred $s i$ face addition of indole was counterintuitive, as it would occur through the more hindered face of the iminium ion. However, it was consistent with the modest selectivity observed with 1a and 1d.

It is known that changes in the catalyst structure and/or reaction conditions might result in unexpected inversions in the sense of induction, as observed for a variety of asymmetric tranformations. ${ }^{16}$ Whenever these often intriguing results take place, it is always desirable to fully understand the responsible non-covalent interactions to re-engineer more efficient catalysts for the desired transformation. Under this philosophy we aimed to rationalize the origins of our experimental findings through DFT calculations. Recent years witnessed the theoretical interest in phosphoric acid-catalyzed FC reactions, ${ }^{17}$ yet there are no reports on the iminium-activated variant. The key step of the FC reaction, which defines de $\mathrm{C}-\mathrm{C}$ bond forming and the facial selectivity, involves the attack of the most nucleophilic atom of the indole (C-2) to the electrophilic $\beta$-carbon of the iminium ion (Scheme 4). 


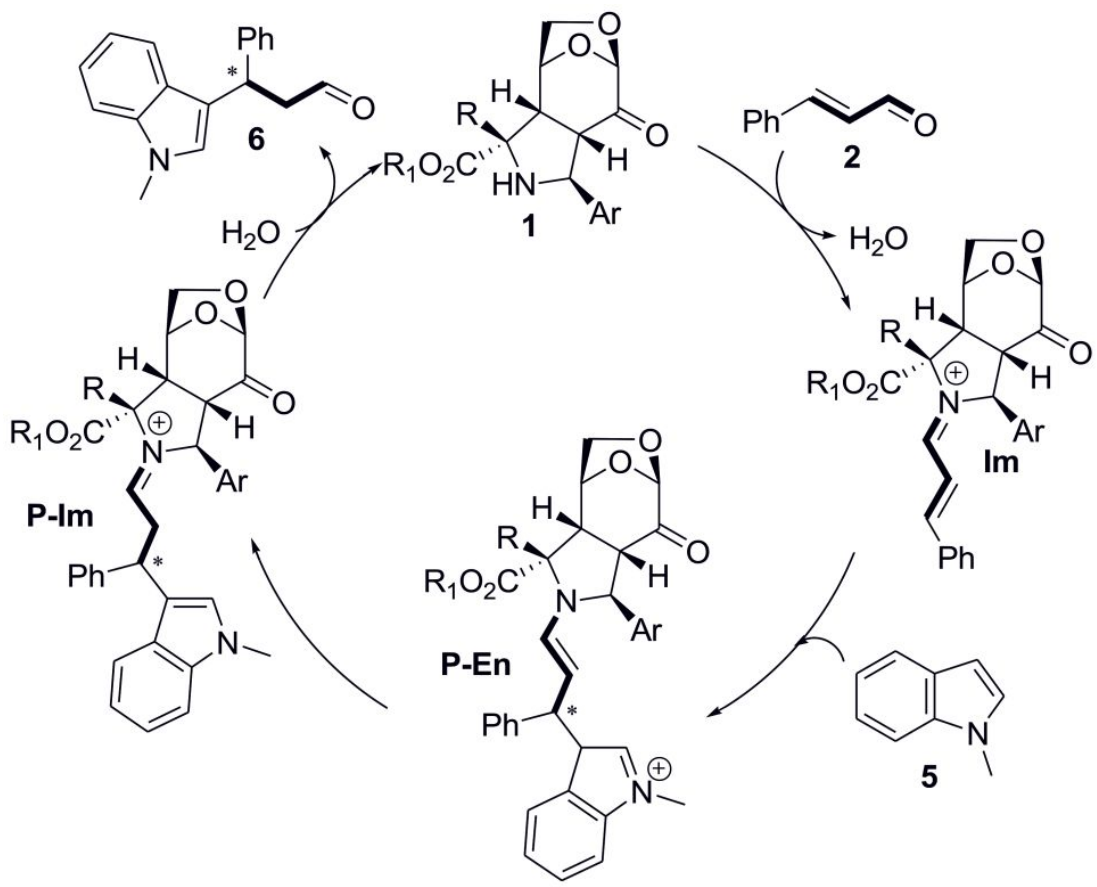

Scheme 4. Proposed catalytic cycle

We started our study by exploring the energetic preferences of this stage through the evaluation of the dimethylamine-organocatalyzed reaction between $(E)$-crotonaldehyde (9) and 5 as a simplified model to reduce the computational cost. To account for the catalytic effect exerted by secondary amines, the corresponding uncatalyzed reaction between 5 and $\mathbf{9}$ was also computed.

After exhaustive exploration of the potential energy surface we located four possible modes of addition, namely: $N$-anti, $N$-syn, $X$-anti and $X$-syn, where $N$ and $X$ accounts for endo and exo orientation of the two interacting systems, respectively, whereas anti and syn refers to the relative position of the methyl groups attached to the nitrogen and C- $\beta$ atoms of the indole and electrophile, respectively. The calculations were carried out at the SMD/B3LYP/6-311+G** level of theory using methanol as solvent. Figure 1 shows the results obtained for the uncatalyzed system, with large activation barriers $(25.7-27.9 \mathrm{kcal} / \mathrm{mol})$ consistent with its low reactivity. The endo orientation is preferred $(\Delta \mathrm{E}=1.9 \mathrm{kcal} / \mathrm{mol}$ and $1.1 \mathrm{kcal} / \mathrm{mol}$ for the syn and anti attacks, respectively). On the other hand, the syn addition is more stable than the anti (0.4 and 1.2 $\mathrm{kcal} / \mathrm{mol}$ for endo and exo approaches, respectively). Upon iminium formation, the activation energies drop by ca. $7.2 \mathrm{kcal} / \mathrm{mol}$ in coherence with the experimentally observed catalytic effect. The higher stabilities for the endo and syn modes remain qualitatively similar than those found 
for the uncatalyzed process. We also tested other popular DFT functionals (such as M06-2X and $\omega \mathrm{B} 97 \mathrm{X}-\mathrm{D})$ and similar trends were computed, though with a larger endo preference and lower activation barriers $\left(\Delta \mathrm{E}^{ \pm}\right.$in range $16.0-22.1 \mathrm{kcal} / \mathrm{mol}$ and $7.0-14.4 \mathrm{kcal} / \mathrm{mol}$ for the uncatalyzed and catalyzed reactions, respectively). Nevertheless, all levels of theory agreed that the $N$-syn channel is the most stable channel.

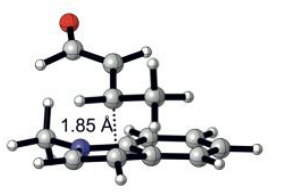

TS-9-N-anti $\Delta \mathrm{E}^{\ddagger}=26.1 \mathrm{kcal} / \mathrm{mol}$

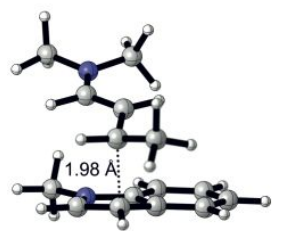

TS-Im9-N-anti $\Delta \mathrm{E}^{\ddagger}=18.8 \mathrm{kcal} / \mathrm{mol}$

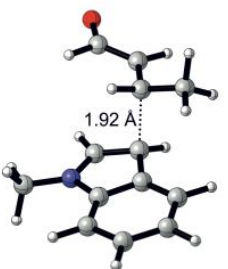

TS-9-X-anti $\Delta \mathrm{E}^{\ddagger}=27.9 \mathrm{kcal} / \mathrm{mol}$

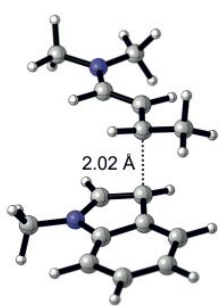

TS-Im9-X-anti $\Delta \mathrm{E}^{\ddagger}=20.7 \mathrm{kcal} / \mathrm{mol}$

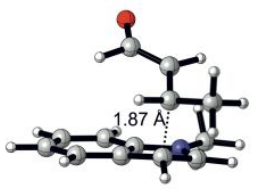

TS-9-N-syn $\Delta \mathrm{E}^{\ddagger}=25.7 \mathrm{kcal} / \mathrm{mol}$
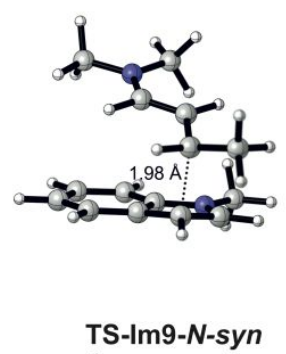
$\Delta \mathrm{E}^{\ddagger}=18.2 \mathrm{kcal} / \mathrm{mol}$

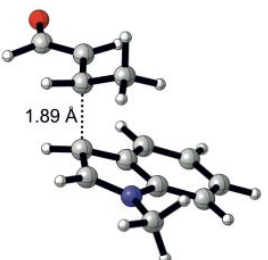

TS-9-X-syn $\Delta \mathrm{E}^{\ddagger}=26.8 \mathrm{kcal} / \mathrm{mol}$

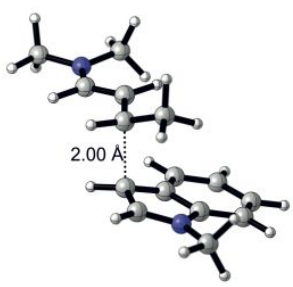

TS-Im9-X-syn $\Delta \mathrm{E}^{\ddagger}=19.4 \mathrm{kcal} / \mathrm{mol}$

Figure 1. Calculated transition structures for the key C-C bond forming stage of the uncatalyzed and dimethylamine-catalyzed FC reaction between 5 and 9 at the SMD/B3LYP/6-311+G** level of theory, with activation barriers in $\mathrm{kcal} / \mathrm{mol}$ and selected distances in angstroms.

Having identified the main energetic features of the simplified system, we focused our attention to the full system by exploring the competing transition structures of the reactions between 9 and $\mathbf{5}$ under $\mathbf{1 b}$ catalysis. Each of the four fundamental modes of addition (Figure 1) can take place through both faces of the resulting $(E)$ - or $(Z)$ configured iminium ion, leading to a total number of 16 transition structures, which in turn exhibit significant conformational freedom. In addition, the size of the full system precluded a full exploration using standard DFT treatment as the computational demand would be prohibitively large for a rapid in silico evaluation of plausible organocatalysts, key aspect in rational design. We therefore considered the use of hybrid schemes to overcome this problem, in which the core region of the TS involving the bond-forming and bond-breaking stages are treated with more rigorous DFT levels whereas the rest of 
the system can be described using less demanding models (such as MM or semiempirical). The ONIOM (our own n-layered integrated molecular orbital and molecular mechanics) method is a hybrid computational approach developed by Morokuma and co-workers that allows to tackle efficiently two- and multiple layered QM/MM and QM/QM calculations. ${ }^{18}$ It uses an extrapolation scheme to estimate the energy of the real system at the high level as: $\mathrm{E}_{(\text {ONIOM,real })}=\mathrm{E}_{\text {(high,model) }}+\mathrm{E}_{(\text {low,real })}-$ $\mathrm{E}_{\text {(low,model). }}$ The good performance at low computational cost makes ONIOM a very popular computational method in the field of asymmetric organocatalysis, ${ }^{19}$ though to the best of our knowledge remained unexplored in secondary amine-catalyzed FC reactions using enals. Figure 2 shows the schematic workflow followed to carry out the calculations. Using the four fundamental modes of addition found for the simplified model at the B3LYP/6-311+G** (Figure 1) we generated the 16 different transition structures. A full conformational sampling was done for each channel at the MM+ level while freezing the coordinates of the high layer region (vide infra). For each conformation, the partition scheme shown in Figure 3 was applied, and each conformer was fully optimized at the ONIOM(B3LYP/6-31G*:AM1) level. Finally, to obtain more accurate results single point energy calculations were taken at the PCM/B3LYP/6$311+\mathrm{G}^{* *}$ level using methanol as solvent. We have previously shown that this level of theory and partition scheme afforded satisfactory predictions at modest computational cost. ${ }^{9}$

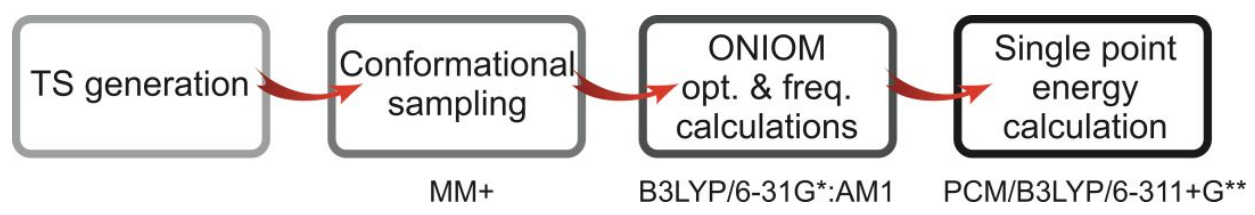

Figure 2. ONIOM calculations workflow.

Figure 3 shows the most stable conformations located for each attack mode. The TSs resulting from the $(E)$-configured iminium were in the average $1.1 \mathrm{kcal} / \mathrm{mol}$ lower in energy than their corresponding $(Z)$ counterparts, consistent with the higher stability of the $(\boldsymbol{E})$-Im precursor experimentally found. In conformity with the results collected for the reduced system, the endo and syn transition structures were in general more stable 
than the corresponding exo and anti ones, respectively. The $S / R$ selectivity calculated at $25{ }^{\circ} \mathrm{C}$ was $76: 24$, close to the experimental $70: 30$ ratio for $\mathbf{1 b}$. The methodology also reproduced the enantioselectivity drop achieved with 1f, featuring a strong withdrawing group (62:38 $S / R$ prediction considering only the $(E)-N$-syn channels, vide infra). A closer inspection of the competing transition structures revealed that the preference towards the $N$-syn-Si attack might be given by weak $\mathrm{CH} / \pi$ interaction between the methyl group of 5 with the phenyl group at C-7. ${ }^{20}$ The mean $\mathrm{CH} / \boldsymbol{\pi}$ distances calculated for TS-1b-(E)-Nsyn-Si and TS-1h-(E)-N-syn-Si were $2.9 \AA$ and $3.3 \AA,{ }^{21 a}$ respectively, showing coherent correlation with the computed $\Delta \mathrm{E}_{R e-S i}$ values $(1.05 \mathrm{kcal} / \mathrm{mol}$ and $0.30 \mathrm{kcal} / \mathrm{mol}$, respectively). Gilmour and co-workers invoked $\mathrm{CH} / \pi$ contacts between the aliphatic $\mathrm{C}-\mathrm{H}$ bonds in MacMillan's type iminium cations and the aromatic system of $\mathbf{5}$ as a key element to enhance proximity of the reagents. ${ }^{11 \mathrm{~b}}$ However, our calculations suggested that such $\beta$-face directing effect of the methyl group at C-8 should not be a dominant interaction in this case, with a mean $\mathrm{CH} / \pi$ distance of $3.9 \AA .{ }^{21 b}$ While B3LYP has been widely used to study $\mathrm{CH} / \pi$-driven interactions, ${ }^{22}$ its limitations to accurately treat dispersion-dominated systems have been pointed out. Taking this into account, we recomputed the $\Delta \mathrm{E}_{R e-S i}$ facial selectivity at the CAM-B3LYP/6-311+G** level. This functional is a long-range corrected version of B3LYP, ${ }^{23}$ which was shown suitable to treat intermolecular $\mathrm{CH} / \pi$ interactions. ${ }^{24}$ The $\Delta \mathrm{E}_{R e-S i}$ values $(1.17 \mathrm{kcal} / \mathrm{mol}$ with $\mathrm{SMD}$, $0.82 \mathrm{kcal} / \mathrm{mol}$ with PCM $)$ suggested that the B3LYP results $\left(\Delta \mathrm{E}_{R e-S i} 1.05 \mathrm{kcal} / \mathrm{mol}\right)$ were not biased. 


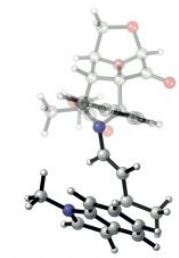

TS-1b-(E)-N-anti-Si $\mathrm{E}_{\text {rel }}=2.07 \mathrm{kcal} / \mathrm{mol}$

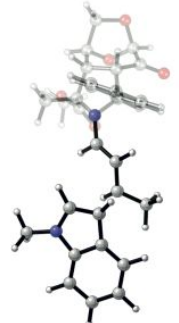

TS-1b-(E)-X-anti-Si $\mathrm{E}_{\text {rel }}=2.61 \mathrm{kcal} / \mathrm{mol}$

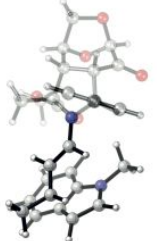

TS-1b-(Z)-N-anti-Si $\mathrm{E}_{\text {rel }}=3.07 \mathrm{kcal} / \mathrm{mol}$

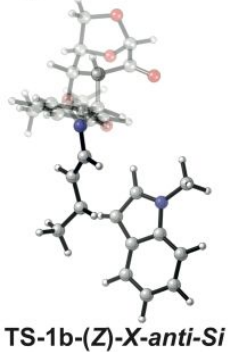

TS-1 $E_{\text {rel }}=2.34 \mathrm{kcal} / \mathrm{mol}$

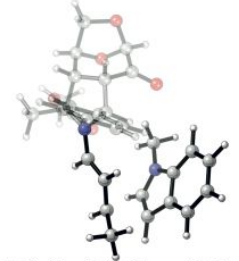

TS-1b-(E)-N-anti-Re $\mathrm{E}_{\text {rel }}=2.38 \mathrm{kcal} / \mathrm{mol}$

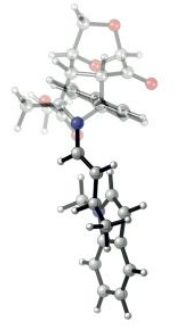

TS-1b-(E)-X-anti-Re $E_{\text {rel }}=1.95 \mathrm{kcal} / \mathrm{mol}$
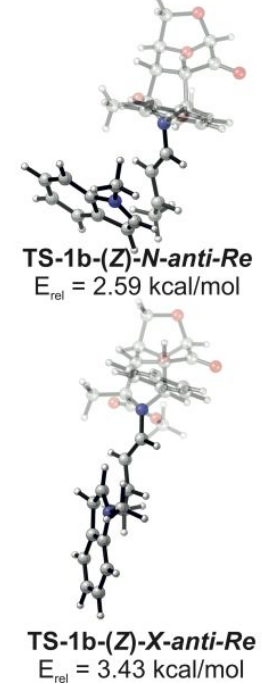
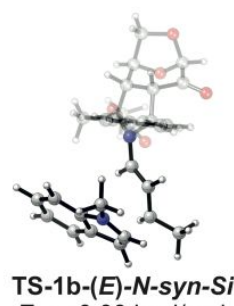

$\mathrm{E}_{\mathrm{rel}}=0.00 \mathrm{kcal} / \mathrm{mol}$

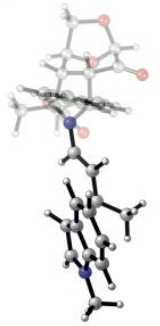

TS-1b-(E)-X-syn-Si $\mathrm{E}_{\mathrm{rel}}=1.14 \mathrm{kcal} / \mathrm{mol}$

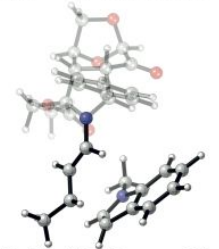

TS-1b-(Z)-N-syn-Si $E_{\text {rel }}=2.33 \mathrm{kcal} / \mathrm{mol}$

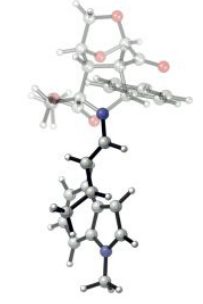

TS-1b-(Z)-X-syn-Si $E_{\text {rel }}=2.55 \mathrm{kcal} / \mathrm{mol}$
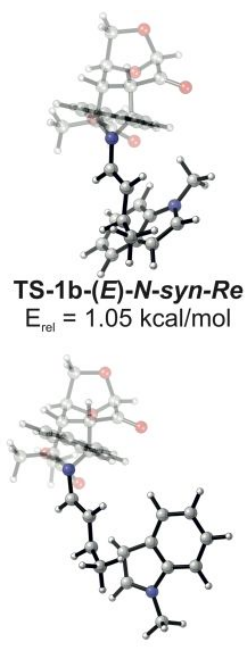

TS-1b-(E)-X-syn-Re $\mathrm{E}_{\text {rel }}=1.34 \mathrm{kcal} / \mathrm{mol}$
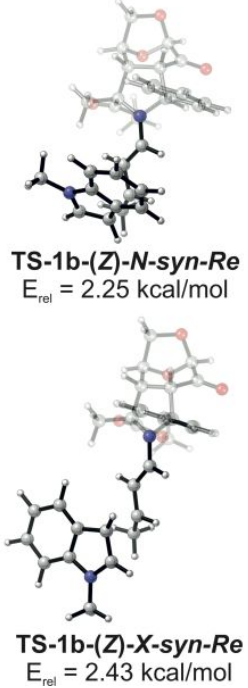

Figure 3. Most stable conformations found for each channel found for the reaction between $\mathbf{5}$ and $\mathbf{9}$ under catalysis of $\mathbf{1 b}$ computed at the PCM/B3LYP/6-311+G**//ONIOM(B3LYP/6-31G*:AM1) level. The full-colored regions indicate the high layer ( $\mathrm{N}$-methylindole and $\alpha, \beta$-unsaturated iminium fragment, up to the pyrrolidine nitrogen) and the gray-out regions indicate the low layer (full catalyst structure without the pyrrolidine nitrogen) in the ONIOM partition scheme.

Perhaps the $\mathrm{CH} / \pi$ interactions have not been the most exploited elements of stereocontrol in asymmetric synthesis, yet there are many reports indicating they can be valuable to improve catalysts' performance. ${ }^{25}$ Hence, we decided to exploit the interplay between the nature of the aromatic group at $\mathrm{C}-7$ with the strength of the hypothetical $\mathrm{CH} / \pi$ contacts. On the other hand, we speculated that the relative stability of the competing $N$-syn-Re channel could be related with the bulkiness of the alkoxy group at $\mathrm{R}_{1}$, with large groups 
leading to more unfavorable steric interactions (Figure 4). In order to prove these structural hypotheses, we evaluated in silico the performance of different catalysts using our previously validated ONIOM approach by changing the nature of the aromatic group at C-7 and the alkoxy group at $\mathrm{R}_{1}$. These changes were intended to understand the effect of the $\mathrm{Ar} / \mathrm{R}_{1}$ groups, and at the same time making the potential catalysts synthetically accessible.
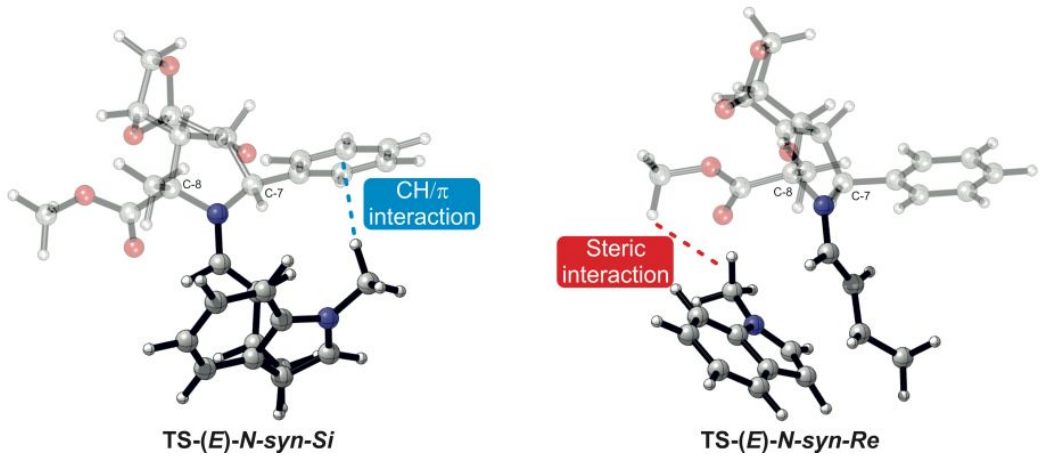

Figure 4. Most stable transition structures found for $S i$ and Re attack of 6 to the iminium cation resulting from the condensation of $\mathbf{8}$ with $\mathbf{1 b}$ with key interactions. The full-colored regions indicate the high layer (N-methylindole and $\alpha, \beta$-unsaturated iminium fragment, up to the pyrrolidine nitrogen) and the gray-out regions indicate the low layer (full catalyst structure without the pyrrolidine nitrogen) in the ONIOM partition scheme.

To reduce the computational cost to a minimum, only the corresponding TS- $(\boldsymbol{E})-\boldsymbol{N}-\boldsymbol{s y n}$ were considered as were found to be the most stable modes of attack. In the case of $\mathbf{1 b}$, the $S / R$ selectivity calculated with this reduced model was higher than that obtained with the full system (85:15 vs 76:24, respectively) because some of the other channels afforded non-negligible contributions (Figure 3). However, we speculated that this trend would remain for the other catalysts.

The compound $\mathbf{1 h}$ (with a 2-naphtyl group at C-7) afforded the highest calculated selectivity among the virtual catalysts featuring $\mathrm{R}_{1}=\mathrm{Me}$ (Figure 5a). In general we observed a good correlation between the mean $\mathrm{CH} / \pi$ distances measured from the corresponding TS-(E)-N-syn-Si geometries with the calculated $\Delta \mathrm{E}_{R e-S i}$ values (Figure $5 \mathrm{~b}$ ) providing further evidence on the participation of $\mathrm{CH} / \pi$ interactions in the relative stabilization of the Si-face transition structures. To reinforce this hypothesis we carried out energy decomposition analyses on three systems (1), $\mathbf{1 f}$ and $\mathbf{1 h})$ that were selected as 
representative examples of transition structures featuring different $\mathrm{CH} / \pi$ distances. The $\Delta \mathrm{E}_{R e-S i}$ values were decomposed into three components, $\Delta \mathrm{E}_{\text {iminium }}, \Delta \mathrm{E}_{\text {indole }}$ and $\Delta \mathrm{E}_{\text {int }}$, where the first two terms are the difference in energy between the iminium and indole fragments in the TS-Re and TS-Si geometries, respectively, whereas the $\Delta \mathrm{E}_{\text {int }}$ is the difference in interaction energies between both fragments at the competing TSs (see Supporting Information for further detail). ${ }^{25 \mathrm{c}}$ The negative values computed for $\Delta \mathrm{E}_{\text {iminium }}$ and $\Delta \mathrm{E}_{\text {indole }}$ indicated that the substrates geometries are more stable in the corresponding TS-Re, presumably because of the higher distortion involved with the attack of the indole through the more hindered face of the iminium ( $s i$ face). However, in the three examples the $\Delta \mathrm{E}_{\text {int }}$ was positive and higher in absolute value, accounting for the $S i$ face attack preference. In the absence of other common non-covalent interactions (such as hydrogen bonding and $\pi$-stacking), the $\Delta \mathrm{E}_{\text {int }} \sim 5 \mathrm{kcal} / \mathrm{mol}$ values were consistent with a possible $\mathrm{CH} / \pi$ interaction as the stabilizing element of the corresponding TS-Si. The inverse qualitative trend observed between $\Delta \mathrm{E}_{\text {int }}$ and the mean $\mathrm{CH} / \pi$ distances, along with natural population analysis (see Supporting Information) supported our proposal.

The selectivity computed for $\mathbf{1 g}$ was lower than expected from the mean $\mathrm{CH} / \pi$ distances, indicating that additional effects might be taking place (such as steric repulsion). Regarding the nature of the $\mathrm{R}_{1}$ group our calculations demonstrated a steady improvement in the selectivity with the size of the alkoxy group by increasing the $\Delta \mathrm{E}_{R e-S i}$ energy gap due to a selective destabilization of the $\mathrm{N}$-syn-Re channel. Taking collectively, the in silico screening suggested the incorporation of a 2-naphtyl group at C-7 and a large group at $R_{1}$ to increase the facial selectivity. These two elements of stereocontrol were combined in virtual catalyst 11, which yielded the highest theoretical enantioselectivity of our set. 


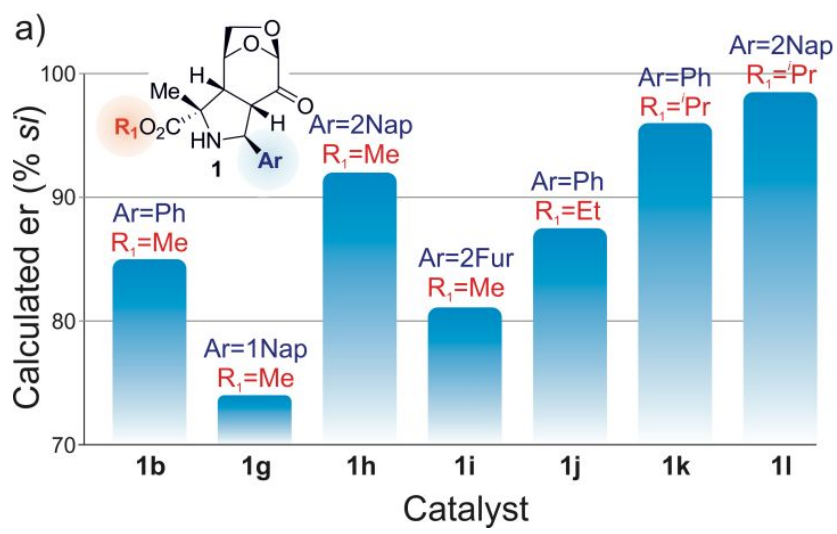

b)

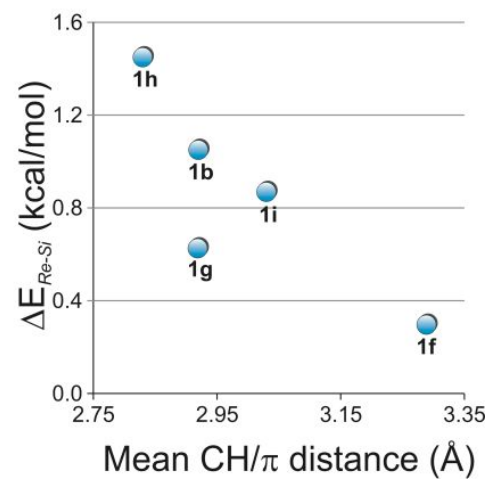

Figure 5. a) Predicted enantioselectivity versus catalyst number. b) Plot of $\Delta \mathrm{E}_{R e-S i}$ energies (in $\mathrm{kcal} / \mathrm{mol}$ ) computed at the PCM/B3LYP/6-311+G**//ONIOM(B3LYP/6-31G*:AM1) level considering only the $(E)-N$-syn channels versus the mean $\mathrm{CH} / \boldsymbol{\pi}$ distances (in $\AA$ ) obtained from the corresponding TS-(E)-N-Syn-Si ONIOM optimized geometries.

With this valuable information in hand, the synthesis of the most prominent catalyst 11 was envisaged following the general procedure previously shown in Scheme 2. Taking advantage of the flexibility of our convergent design to introduce structural diversity in different areas of the molecule, we also prepared the analogues $\mathbf{1 m - 0}$ in good overall yields (62-81\%) featuring other bulky groups at $\mathrm{R}_{1}$. The key azomethine ylide precursors could be easily synthesized by condensation of commercially available 2-naphtaldehyde with the corresponding aminoester prepared by esterification of alanine with different alcohols in acid media (Scheme 5).

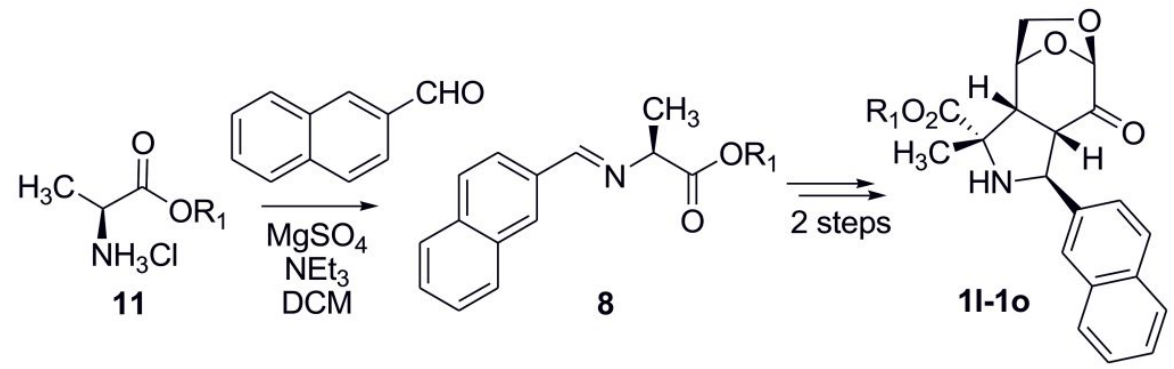

Scheme 5. Synthesis of the most promising catalysts 11-o according to the in silico screening.

In excellent agreement with the computational findings the selectivities observed with these new series of pyrrolidines were higher than those previously explored (up to 81:19), Table 2. Despite all catalysts affording quite similar results, we kept 10 for final optimization of the reaction conditions. The best results were achieved using TFA as co- 
catalyst and low temperature $\left(-50^{\circ} \mathrm{C}\right)$, yielding the desired product in $92: 8$ er, closer to the enantioselectivity achieved with the optimal MacMillan's catalyst for the same transformation. ${ }^{11 a}$ Moreover, when comparing the results obtained with the variety of catalysts evaluated in the reaction between $\mathbf{2}$ and $\mathbf{5}$ via iminium-activation, ${ }^{10,11}$ the results obtained with 10 were significant. Perhaps even more remarkable is the fact that we were able to re-engineer a very poor catalyst synergistically combining reduced experimentation with fast calculations, highlighting the power of this underexplored approach.

Table 2. Results obtained with catalysts $\mathbf{1 1 - 0}$ on the FC reaction between $\mathbf{2}$ and $\mathbf{5}^{\mathrm{a}}$

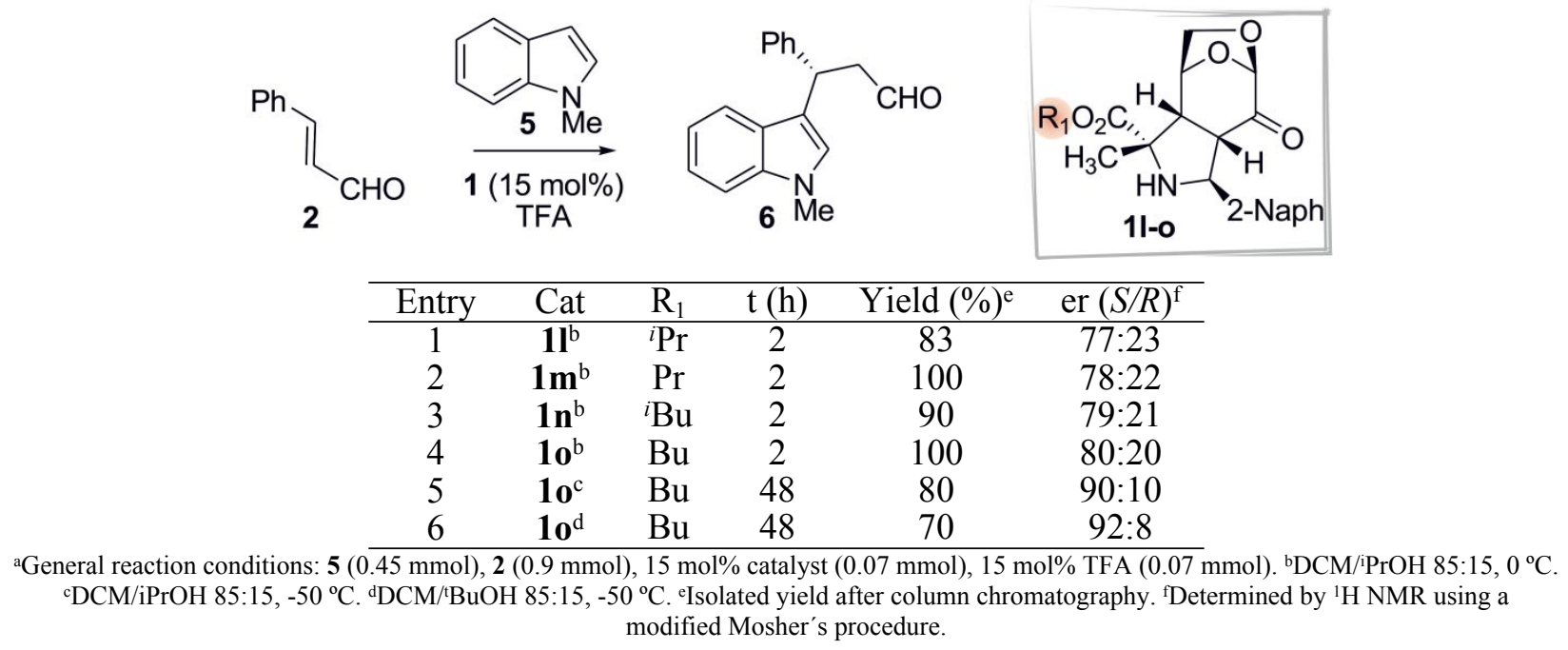

In a final effort to validate the predictive power of our calculations, we synthesized and evaluated catalysts $\mathbf{1 h}\left(\mathrm{Ar}=2\right.$-naphtyl, $\left.\mathrm{R}_{1}=\mathrm{Me}\right), \mathbf{1 i}\left(\mathrm{Ar}=2\right.$-furyl, $\left.\mathrm{R}_{1}=\mathrm{Me}\right)$ and $\mathbf{1} \mathbf{k}(\mathrm{Ar}=\mathrm{Ph}$, $\mathrm{R}_{1}={ }^{\mathrm{i}} \mathrm{Pr}$ ). Despite the experimental selectivities were lower than computed (expected because a reduced system of only the two (E)-N-syn channels was employed), they followed the same trends computationally found (Figure 6). We also synthesized catalyst 1p (Ar=1-napthyl, $\mathrm{R}_{1}=i \operatorname{Pr}$ ) to prove that the introduction of a 1-naphtyl group would be detrimental. The observed selectivity was 61:39, lower than those obtained with 1k ( $\left.\mathrm{Ar}=\mathrm{Ph}, \mathrm{R}_{1}={ }^{i} \mathrm{Pr}\right)$ and $\mathbf{1 l}\left(\mathrm{Ar}=2\right.$-naphtyl, $\left.\mathrm{R}_{1}={ }^{i} \mathrm{Pr}\right)$ in accordance with the predictions. 


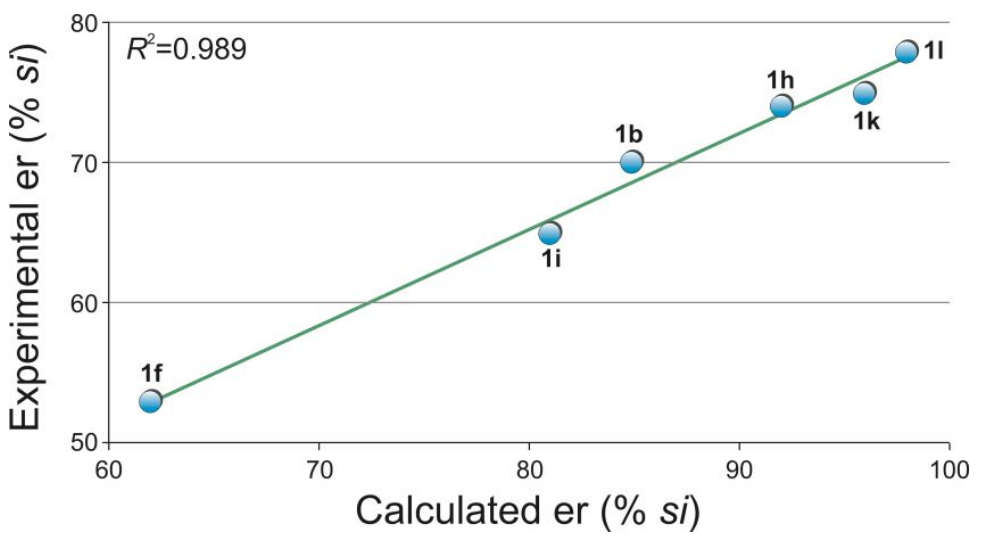

Figure 6. Experimental validation of the computational predictions collected using the reaction conditions indicated in Table 1.

\section{Conclusions}

Following a rational design approach we developed a new levoglucosenone-derived organocatalyst for asymmetric Friedel-Crafts alkylation of indoles. The use of fast DFT calculations allowed the identification of the key interactions affecting the enantioselectivity of the process under study. With this information, the potential catalysts were screened prior to invest effort in the synthesis and evaluation stage. Only the most promising candidates were next synthesized and successfully tested experimentally. This strategy, which to the best of our knowledge has been little explored in the field of asymmetric organocatalysis, could significantly speed up the discovery of efficient catalysts for useful chemical transformations.

\section{Experimental Section}

All reagents and solvents were used directly as purchased or purified according to standard procedures. Analytical thin layer chromatography was carried out using commercial silica gel plates and visualization was effected with short wavelength UV light $(254 \mathrm{~nm})$ and a p-anysaldehyde solution $(2.5 \mathrm{~mL}$ of p-anysaldehyde $+2.5 \mathrm{~mL}$ of $\mathrm{H}_{2} \mathrm{SO}_{4}+0.25 \mathrm{~mL}$ of $\mathrm{AcOH}+95 \mathrm{~mL}$ of $\mathrm{EtOH}$ ) with subsequent heating. Column chromatography was performed with silica gel $60 \mathrm{H}$, slurry packed, run under low pressure of nitrogen using mixtures of hexane and ethyl acetate. NMR spectra were recorded at $300 \mathrm{MHz}$ for ${ }^{1} \mathrm{H}$, and $75 \mathrm{MHz}$ for ${ }^{13} \mathrm{C}$ with $\mathrm{CDCl}_{3}$ as solvent and $\left(\mathrm{CH}_{3}\right)_{4} \mathrm{Si}$ 
$\left({ }^{1} \mathrm{H}\right)$ or $\mathrm{CDCl}_{3}\left({ }^{13} \mathrm{C}, 76.9 \mathrm{ppm}\right)$ as internal standards. Chemical shifts are reported in delta ( $\delta)$ units in parts per million (ppm) and splitting patterns are designated as s, singlet; d, doublet; $\mathrm{t}$, triplet; q, quartet; $\mathrm{m}$, multiplet and br, broad. Coupling constants are recorded in Hertz $(\mathrm{Hz})$. Isomeric ratios were determined by ${ }^{1} \mathrm{H}$ NMR analysis. The structures of the products were determined by a combination of spectroscopic methods such as IR, 1D and 2D NMR (including NOE, COSY, HSQC and HMBC experiments) and HRMS. The ${ }^{1} \mathrm{H}$ and ${ }^{13} \mathrm{C}$ NMR peak assignment was based on COSY, HSQC and HMBC experiments. Infrared spectra were recorded using sodium chloride plates pellets. Absorbance frequencies are recorded in reciprocal centimeters $\left(\mathrm{cm}^{-1}\right)$. High resolution mass spectra (HRMS) were obtained on a TOF-Q LC-MS spectrometer. Optical rotations were determined using a digital polarimeter in $100 \mathrm{~mm}$ cells and the sodium D line $(589 \mathrm{~nm})$ at room temperature in the solvent and concentration indicated. The melting points are uncorrected. Levoglucosenone (7) was prepared from our microwave-assisted pyrolysis of acid-pretreated microcrystalline cellulose. ${ }^{26}$ The $\alpha$-imino esters 8 were prepared by condensation of the alanine, phenylalanine or leucine ester hydrochloride and the corresponding aldehyde according to known procedures. ${ }^{27}$ The aminoacid ester hydrochlorides were synthesized by bubbling $\mathrm{HCl}(\mathrm{g})$ to a solution of the aminoacid in the corresponding alcohol following known procedures. ${ }^{28}$

General Procedure for the synthesis of 1 . To a solution of $7(126 \mathrm{mg}, 1 \mathrm{mmol})$ and the corresponding $\alpha$-iminoester $8(1.5 \mathrm{mmol})$ in dry $\mathrm{MeCN}(10 \mathrm{~mL})$ was successively added AgOAc (50 mg, $0.3 \mathrm{mmol})$ and DBU $(45 \mu \mathrm{L}, 0.3 \mathrm{mmol})$. The mixture was stirred for 1 hour at room temperature under argon atmosphere and in the absence of light (flask covered with aluminium foil). After filtration through Celite, the filtrate was concentrated to dryness under reduced pressure. The residue was filtered through a shot path of silica gel, concentrated to dryness, and dissolved in a 95:5 $\mathrm{CHCl}_{3} / \mathrm{TFA}$ solution $(2 \mathrm{~mL})$. The resulting solution was stirred at $110{ }^{\circ} \mathrm{C}$ in the microwave reactor until complete conversion of the starting material (typically $40 \mathrm{~min}$ ). Microwave heating was performed in a CEM Discover ${ }^{\circledR}$ System using septum-sealed $10 \mathrm{~mL}$ vials for high-pressure reaction conditions with stirring and IR-monitored temperature control. Using the Standard mode, once the system achieved the desired temperature (typically, in less than one minute), the applied power varied to maintain the temperature fixed during the experiment. The 
solvent was removed under reduced pressure, and the crude was purified by column chromatography on silica gel eluting with petroleum ether-ethyl acetate mixture (100:0 to $80: 20, \mathrm{v} / \mathrm{v}$ ) to afford pure compound. The analytical data of $\mathbf{1 a}, \mathbf{1 b}, \mathbf{1 c}, \mathbf{1 e}, \mathbf{1 f}, \mathbf{1 h}$ and $\mathbf{1 i}$ has been already published. , $^{9}$

1d: Purification by flash column chromatography on silica gel eluting with petroleum ether-ethyl acetate mixture (100:0 to 80:20, v/v) afforded the title compound as colorless oil; yield: $0.266 \mathrm{~g}, 74 \%$; $[\alpha]_{\mathrm{D}}-101.1$ (c 1.22, $\mathrm{CHCl}_{3}$ ); IR (film) $v_{\max } 3354,2954,2851$, 1736, 1732, 1493,1454, 1217, 1161, 1119, 1026, $984 \mathrm{~cm}^{-1} ;{ }^{1} \mathrm{H} \mathrm{NMR}\left(\mathrm{CDCl}_{3}, 300 \mathrm{MHz}\right) \delta$ 7.49-7.42 (m, 2H), 7.29-7.12 (m, 3H), $5.06(\mathrm{~d}, J 4.8 \mathrm{~Hz}, 1 \mathrm{H}), 5.03(\mathrm{~s}, 1 \mathrm{H}), 4.88(\mathrm{~d}, J 4.9$ Hz, 1H), 3.88 (dd,J 7.3 Hz, J4.9 Hz, 1H), 3.79 (dd, J7.3 Hz, J 0.8 Hz, 1H), 3.63 (s, 3H), $2.88(\mathrm{dd}, J 10.3 \mathrm{~Hz}, J 4.7 \mathrm{~Hz}, 1 \mathrm{H}), 2.46$ (d, J $10.3 \mathrm{~Hz}, 1 \mathrm{H}), 2.20$ (dd, J 13.4 Hz, J 6.5 Hz, 1H), 1.82-1.66 (m, 1H), $1.41(\mathrm{dd}, J 13.4 \mathrm{~Hz}, J 6.5 \mathrm{~Hz}, 1 \mathrm{H}), 0.94$ (d, J $6.5 \mathrm{~Hz}, 3 \mathrm{H}), 0.84$ (d, $J 6.5 \mathrm{~Hz}, 3 \mathrm{H}) ;{ }^{13} \mathrm{C}\left\{{ }^{1} \mathrm{H}\right\} \mathrm{NMR}\left(\mathrm{CDCl}_{3}, 75 \mathrm{MHz}\right) \delta 198.4(\mathrm{C}), 176.0(\mathrm{C}), 145.4(\mathrm{C}), 128.3$ $(\mathrm{CH}, 2 \mathrm{C}), 126.8(\mathrm{CH}), 126.3(\mathrm{CH}, 2 \mathrm{C}), 100.7(\mathrm{CH}), 72.3(\mathrm{CH}), 69.7(\mathrm{C}), 68.9\left(\mathrm{CH}_{2}\right), 60.0$ $(\mathrm{CH}), 55.4(\mathrm{CH}), 52.5(\mathrm{CH}), 52.1\left(\mathrm{CH}_{3}\right), 47.8\left(\mathrm{CH}_{2}\right), 25.5(\mathrm{CH}), 24.1\left(\mathrm{CH}_{3}\right), 23.3\left(\mathrm{CH}_{3}\right)$; HRMS (ESI) $m / z$ : [M+H] $]^{+}$Calcd for $\mathrm{C}_{20} \mathrm{H}_{26} \mathrm{NO}_{5}$ 360.1805; Found 360.1807.

11: Purification by flash column chromatography on silica gel eluting with petroleum ether-ethyl acetate mixture (100:0 to 80:20, v/v) afforded the title compound as yellowish oil; yield: $0.301 \mathrm{~g}$, $76 \%$; $[\alpha]_{\mathrm{D}}-64.5$ (c 0.98, $\mathrm{CHCl}_{3}$ ); IR (film) $v_{\max } 3350,2978,2903,1736,1721,1601,1464,1294$, 1229, 1167, 1115, $986 \mathrm{~cm}^{-1} ;{ }^{1} \mathrm{H}$ NMR $\left(\mathrm{CDCl}_{3}, 300 \mathrm{MHz}\right) \delta 7.99(\mathrm{~s}, 1 \mathrm{H}), 7.88-7.75$ (m, 3H), 7.62 (dd, J 8.6 Hz, J 1.6 Hz, 1H), 7.50-7.38 (m, 2H), 5.29 (d, J 4.6 Hz, 1H), 5.14 (s, 1H), 5.09-4.93 (m, 2H), 3.97 (dd, J 7.4 Hz, J 5.0 Hz, 1H), 3.89 (d, J 7.4 Hz, 1H), 3.07 (dd, J 10.3 Hz, J 4.6 Hz, 1H), $2.58(\mathrm{~d}, J 10.3 \mathrm{~Hz}, 1 \mathrm{H}), 1.63(\mathrm{~s}, 3 \mathrm{H}), 1.29(\mathrm{~d}, J 6.3 \mathrm{~Hz}, 3 \mathrm{H}), 1.26(\mathrm{~d}, J 6.3,3 \mathrm{H}) ;{ }^{13} \mathrm{C}\left\{{ }^{1} \mathrm{H}\right\}$ NMR ( $\left.\mathrm{CDCl}_{3}, 75 \mathrm{MHz}\right) \delta 198.5(\mathrm{C}), 175.1$ (C), 142.6 (C), 133.2 (C), 132.6 (C), $128.2(\mathrm{CH})$, $127.8(\mathrm{CH}), 127.5(\mathrm{CH}), 125.9(\mathrm{CH}), 125.4(\mathrm{CH}), 124.9(\mathrm{CH}), 124.6(\mathrm{CH}), 100.8(\mathrm{CH}), 71.9$ $(\mathrm{CH}), 69.4(\mathrm{CH}), 68.9\left(\mathrm{CH}_{2}\right), 66.7(\mathrm{C}), 60.3(\mathrm{CH}), 55.0(\mathrm{CH}), 53.2(\mathrm{CH}), 25.8\left(\mathrm{CH}_{3}\right), 21.6$ $\left(\mathrm{CH}_{3}\right), 21.4\left(\mathrm{CH}_{3}\right)$; HRMS (ESI) m/z: [M+H] ${ }^{+}$Calcd for $\mathrm{C}_{23} \mathrm{H}_{26} \mathrm{NO}_{5}$ 396.1805; Found 396.1799.

1m: Purification by flash column chromatography on silica gel eluting with petroleum etherethyl acetate mixture (100:0 to 80:20, v/v) afforded the title compound as colorless oil; yield: $0.246 \mathrm{~g}, 62 \% ;[\alpha]_{\mathrm{D}}-56.7\left(c \quad 0.76, \mathrm{CHCl}_{3}\right)$; IR (film) $v_{\max } 3348,2968,2359,1732,1730$, 1506,1462, 1261, 1227, 1165, 1115, $984 \mathrm{~cm}^{-1}$; ${ }^{1} \mathrm{H}$ NMR $\left(\mathrm{CDCl}_{3}, 300 \mathrm{MHz}\right) \delta 7.99(\mathrm{~s}, 1 \mathrm{H}), 7.87-$ 
$7.77(\mathrm{~m}, 3 \mathrm{H}), 7.61(\mathrm{dd}, J 8.5 \mathrm{~Hz}, J 1.6 \mathrm{~Hz}, 1 \mathrm{H}), 7.50-7.39(\mathrm{~m}, 2 \mathrm{H}), 5.32(\mathrm{~d}, J 4.6 \mathrm{~Hz}, 1 \mathrm{H}), 5.14$ (s, 1H), 4.94 (d, $J 4.9 \mathrm{~Hz}, 1 \mathrm{H}), 4.16-3.93(\mathrm{~m}, 3 \mathrm{H}), 3.89$ (d, $J 7.3 \mathrm{~Hz}, 1 \mathrm{H}), 3.07$ (dd, $J 10.2 \mathrm{~Hz}, J$ $4.5 \mathrm{~Hz}, 1 \mathrm{H}), 2.59(\mathrm{~d}, J 10.2 \mathrm{~Hz}, 1 \mathrm{H}), 1.79-1.60(\mathrm{~m}, 5 \mathrm{H}), 0.98(\mathrm{t}, J 7.4 \mathrm{~Hz}, 3 \mathrm{H}) ;{ }^{13} \mathrm{C}\left\{{ }^{1} \mathrm{H}\right\} \quad \mathrm{NMR}$ $\left(\mathrm{CDCl}_{3}, 75 \mathrm{MHz}\right) \delta 198.3(\mathrm{C}), 175.8(\mathrm{C}), 142.6(\mathrm{C}), 133.2(\mathrm{C}), 132.6(\mathrm{C}), 128.2(\mathrm{CH}), 127.8$ $(\mathrm{CH}), 127.5(\mathrm{CH}), 125.9(\mathrm{CH}), 125.5(\mathrm{CH}), 124.9(\mathrm{CH}), 124.6(\mathrm{CH}), 100.8(\mathrm{CH}), 72.0(\mathrm{CH})$, $68.9\left(\mathrm{CH}_{2}\right), 67.2\left(\mathrm{CH}_{2}\right), 66.7(\mathrm{C}), 60.3(\mathrm{CH}), 54.9(\mathrm{CH}), 53.2(\mathrm{CH}), 25.4\left(\mathrm{CH}_{3}\right), 21.6\left(\mathrm{CH}_{2}\right), 10.4$ $\left(\mathrm{CH}_{3}\right)$; HRMS (ESI) $m / z$ : [M+H] $]^{+}$Calcd for $\mathrm{C}_{23} \mathrm{H}_{26} \mathrm{NO}_{5} 396.1805$; Found 396.1808 .

1n: Purification by flash column chromatography on silica gel eluting with petroleum ether-ethyl acetate mixture (100:0 to 80:20, v/v) afforded the title compound as colorless oil; yield: $0.326 \mathrm{~g}$, $80 \%$; $[\alpha]_{\mathrm{D}}-58.2$ (c 0.99, $\mathrm{CHCl}_{3}$ ); IR (film) $v_{\max } 3348,2965,2874,1736,1730,1601,1506,1470$, 1261, 1165, 1113, 1042, $984 \mathrm{~cm}^{-1} ;{ }^{1} \mathrm{H}$ NMR $\left(\mathrm{CDCl}_{3}, 300 \mathrm{MHz}\right) \delta 7.99(\mathrm{~s}, 1 \mathrm{H}), 7.87-7.76(\mathrm{~m}$, $3 \mathrm{H}), 7.61(\mathrm{dd}, J 8.5 \mathrm{~Hz}, J 1.6 \mathrm{~Hz}, 1 \mathrm{H}), 7.50-7.38(\mathrm{~m}, 2 \mathrm{H}), 5.32(\mathrm{~d}, J 4.5 \mathrm{~Hz}, 1 \mathrm{H}), 5.13(\mathrm{~s}, 1 \mathrm{H})$, 4.94 (d, $J 4.8 \mathrm{~Hz}, 1 \mathrm{H}), 4.00-3.78$ (m, 4H), 3.06 (dd, $J 10.2 \mathrm{~Hz}, J 4.5 \mathrm{~Hz}, 1 \mathrm{H}), 2.58$ (d, $J 10.2 \mathrm{~Hz}$, $1 \mathrm{H}), 2.06-1.90(\mathrm{~m}, 1 \mathrm{H}), 1.65(\mathrm{~s}, 3 \mathrm{H}), 0.98(\mathrm{~d}, J 6.7 \mathrm{~Hz}, 3 \mathrm{H}), 0.97(\mathrm{~d}, J 6.7 \mathrm{~Hz}, 3 \mathrm{H}) ;{ }^{13} \mathrm{C}\left\{{ }^{1} \mathrm{H}\right\}$ NMR ( $\left.\mathrm{CDCl}_{3}, 75 \mathrm{MHz}\right) \delta 198.2(\mathrm{C}), 175.8(\mathrm{C}), 142.6(\mathrm{C}), 133.2(\mathrm{C}), 132.6(\mathrm{C}), 128.2(\mathrm{CH})$, $127.8(\mathrm{CH}), 127.5(\mathrm{CH}), 125.9(\mathrm{CH}), 125.4(\mathrm{CH}), 124.9(\mathrm{CH}), 124.6(\mathrm{CH}), 100.7(\mathrm{CH}), 72.0$ $(\mathrm{CH}), 71.7\left(\mathrm{CH}_{2}\right), 68.8\left(\mathrm{CH}_{2}\right), 66.7(\mathrm{C}), 60.3(\mathrm{CH}), 54.8(\mathrm{CH}), 53.1(\mathrm{CH}), 27.4(\mathrm{CH}), 25.4$ $\left(\mathrm{CH}_{3}\right), 19.1\left(\mathrm{CH}_{3}, 2 \mathrm{C}\right)$; HRMS (ESI) $\mathrm{m} / z$ : $[\mathrm{M}+\mathrm{H}]^{+}$Calcd for $\mathrm{C}_{24} \mathrm{H}_{28} \mathrm{NO}_{5}$ 410.1962; Found 410.1969 .

10: Purification by flash column chromatography on silica gel eluting with petroleum ether-ethyl acetate mixture (100:0 to 80:20, v/v) afforded the title compound as colorless oil; yield: $0.332 \mathrm{~g}$, $81 \%$; $[\alpha]_{\mathrm{D}}-72.0$ (c 1.16, $\mathrm{CHCl}_{3}$ ); IR (film) $v_{\max } 3348,2961,2872,1731,1730,1601,1506,1458$, $1375,1261,1229,1165,1124,986 \mathrm{~cm}^{-1}$; ${ }^{1} \mathrm{H} \mathrm{NMR}\left(\mathrm{CDCl}_{3}, 300 \mathrm{MHz}\right) \delta 7.98(\mathrm{~s}, 1 \mathrm{H}), 7.88-7.74$ (m, 3H), 7.61 (dd, $J 8.5 \mathrm{~Hz}, J 1.5 \mathrm{~Hz}, 1 \mathrm{H}), 7.50-7.38(\mathrm{~m}, 2 \mathrm{H}), 5.30(\mathrm{~d}, J 4.5 \mathrm{~Hz}, 1 \mathrm{H}), 5.12(\mathrm{~s}$, 1H), 4.91 (d, J $5.0 \mathrm{~Hz}, 1 \mathrm{H}), 4.19-4.00$ (m, 2H), 3.94 (dd, J 7.4 Hz, J 5.0 Hz, 1H), 3.85 (d, J 7.4 Hz, 1H), 3.05 (dd, $J 10.2 \mathrm{~Hz}, J 4.5 \mathrm{~Hz}, 1 \mathrm{H}), 2.55$ (d, $J 10.2 \mathrm{~Hz}, 1 \mathrm{H}), 1.71-1.58$ (m, 5H), 1.41 (sxt, $J 7.4,2 \mathrm{H}), 0.96(\mathrm{t}, J 7.4 \mathrm{~Hz}, 3 \mathrm{H}) ;{ }^{13} \mathrm{C}\left\{{ }^{1} \mathrm{H}\right\} \operatorname{NMR}\left(\mathrm{CDCl}_{3}, 75 \mathrm{MHz}\right) \delta 198.3(\mathrm{C}), 175.8(\mathrm{C})$, $142.6(\mathrm{C}), 133.2(\mathrm{C}), 132.6(\mathrm{C}), 128.1(\mathrm{CH}), 127.7(\mathrm{CH}), 127.5(\mathrm{CH}), 125.9(\mathrm{CH}), 125.4(\mathrm{CH})$, $124.8(\mathrm{CH}), 124.5(\mathrm{CH}), 100.7(\mathrm{CH}), 71.9(\mathrm{CH}), 68.8\left(\mathrm{CH}_{2}\right), 66.6(\mathrm{C}), 65.4\left(\mathrm{CH}_{2}\right), 60.3(\mathrm{CH})$, $54.8(\mathrm{CH}), 53.1(\mathrm{CH}), 30.2\left(\mathrm{CH}_{2}\right), 25.3\left(\mathrm{CH}_{3}\right), 19.1\left(\mathrm{CH}_{2}\right), 13.6\left(\mathrm{CH}_{3}\right)$; HRMS (ESI) $m / z$ : $[\mathrm{M}+\mathrm{H}]^{+}$Calcd for $\mathrm{C}_{24} \mathrm{H}_{28} \mathrm{NO}_{5} 410.1962$; Found 410.1950 . 
1k: Purification by flash column chromatography on silica gel eluting with petroleum ether-ethyl acetate mixture (100:0 to 80:20, v/v) afforded the title compound as colorless oil; yield: $0.252 \mathrm{~g}$, $73 \%$; $[\alpha]_{\mathrm{D}}-86.5$ (c 0.96, $\mathrm{CHCl}_{3}$ ); IR (film) $v_{\max } 3347,2978,2905,1736,1722,1491,1260,1229$, 1165, 1107, 1026, $984 \mathrm{~cm}^{-1} ;{ }^{1} \mathrm{H}$ NMR $\left(\mathrm{CDCl}_{3}, 300 \mathrm{MHz}\right) \delta$ 7.55-7.48 (m, 2H), 7.37-7.18 (m, 3H), 5.14-5.09 (m, 2H), 5.06-4.90 (m, 2H), 3.96 (dd, J 7.4 Hz, J 5.0 Hz, 1H), 3.88 (d, J 7.4 Hz, 1H), 3.00 (dd, J 10.3 Hz, J 4.7Hz, 1H), 2.52 (d, J 10.3 Hz, 1H), 1.58 (s, 3H), 1.27 (d, J 6.3 Hz, 3H), $1.23(\mathrm{~d}, J 6.3,3 \mathrm{H}) ;{ }^{13} \mathrm{C}\left\{{ }^{1} \mathrm{H}\right\} \mathrm{NMR}\left(\mathrm{CDCl}_{3}, 75 \mathrm{MHz}\right) \delta 198.5(\mathrm{C}), 175.0$ (C), 145.2 (C), $128.3(\mathrm{CH}, 2 \mathrm{C}), 126.8(\mathrm{CH}), 126.3(\mathrm{CH}, 2 \mathrm{C}), 100.7(\mathrm{CH}), 71.8(\mathrm{CH}), 69.3(\mathrm{CH}), 68.9\left(\mathrm{CH}_{2}\right)$, $66.6(\mathrm{C}), 60.2(\mathrm{CH}), 54.9(\mathrm{CH}), 53.2(\mathrm{CH}), 25.6\left(\mathrm{CH}_{3}\right), 21.6\left(\mathrm{CH}_{3}\right), 21.3\left(\mathrm{CH}_{3}\right)$; HRMS (ESI) $m / z:[\mathrm{M}+\mathrm{H}]^{+}$Calcd for $\mathrm{C}_{19} \mathrm{H}_{24} \mathrm{NO}_{5} 346.1649$; Found 346.1646.

1p: Purification by flash column chromatography on silica gel eluting with petroleum ether-ethyl acetate mixture (100:0 to 80:20, v/v) afforded the title compound as colorless oil; yield: $0.269 \mathrm{~g}$, $68 \% ;[\alpha]_{\mathrm{D}}-60.3$ (c 0.45, $\mathrm{CHCl}_{3}$ ); IR (film) $v_{\max } 3362,2978,2934,1736,1730,1595,1454,1373$, 1258, 1231, 1167, 1117, $982 \mathrm{~cm}^{-1} ;{ }^{1} \mathrm{H}$ NMR $\left(\mathrm{CDCl}_{3}, 300 \mathrm{MHz}\right) \delta 8,48(\mathrm{~d}, J$ 8,4 Hz, 1H), 7,95 (d, $J$ 7,2 Hz, 1H), 7.89-7.82 (m, 1H), $7.75(\mathrm{~d}, J 8.1 \mathrm{~Hz}, 1 \mathrm{H}), 7.58-7.40$ (m, 3H), $5.94(\mathrm{~d}, J 3.1 \mathrm{~Hz}$, 1H), 5.14 (s, 1H), 5.03 (sept, J $6.3 \mathrm{~Hz}, 1 \mathrm{H}), 4.95$ (d J $5.0 \mathrm{~Hz}, 1 \mathrm{H}), 3.92$ (dd, J 7.4 Hz, J 5.0Hz, 1H), $3.82(\mathrm{~d}, J 7.4 \mathrm{~Hz}, 1 \mathrm{H}), 3.14(\mathrm{dd}, J 10.0 \mathrm{~Hz}, J 3.1 \mathrm{~Hz}, 1 \mathrm{H}), 2.62$ (d, J $10.0 \mathrm{~Hz}, 1 \mathrm{H}), 1.68$ (s, 3H), 1.31 (d, J $6.3 \mathrm{~Hz}, 3 \mathrm{H}), 1.29$ (d, J $6.3 \mathrm{~Hz}, 3 \mathrm{H}) ;{ }^{13} \mathrm{C}\left\{{ }^{1} \mathrm{H}\right\} \mathrm{NMR}\left(\mathrm{CDCl}_{3}, 75 \mathrm{MHz}\right) \delta 198,3(\mathrm{C})$, 175,25 (C), 140,9 (C), 133,8 (C), 130,7 (C), 128,5 (CH), 127,6 (CH), 126,1 (CH), 125,5 (CH), 125,2 $(\mathrm{CH}), 123,7(\mathrm{CH}), 123,4(\mathrm{CH}), 101,0(\mathrm{CH}), 72,0(\mathrm{CH}), 69,6(\mathrm{CH}), 68,7\left(\mathrm{CH}_{2}\right), 66,7(\mathrm{C})$, 56,1 (CH), 55,5 (CH), 53,4 (CH), 26,4 $\left(\mathrm{CH}_{3}\right), 21,6\left(\mathrm{CH}_{3}\right), 21,4\left(\mathrm{CH}_{3}\right) ; \mathrm{HRMS}(\mathrm{ESI}) \mathrm{m} / z:[\mathrm{M}+\mathrm{H}]^{+}$ Calcd for $\mathrm{C}_{23} \mathrm{H}_{26} \mathrm{NO}_{5} 396.1805$; Found 396.1797.

General procedure for the organocatalyzed Friedel-Crafts reaction. To a solution of amine $1(0.07 \mathrm{mmol})$ in the solvent indicated in Tables 1 and $2(0.7 \mathrm{~mL})$ were added TFA $(0.06 \mathrm{mmol})$ and $(E)$-cinnamaldehyde $(0.9 \mathrm{mmol})$ in that order. The solution was stirred at the corresponding temperature for 10 minutes, and $\mathrm{N}$-methylindole $(0.45 \mathrm{mmol})$ was added. After the time indicated in Tables 1 and 2, the reaction was quenched by the addition of $\mathrm{NEt}_{3}$. The solvent was removed under reduced pressure and the crude was purified by column chromatography on silica gel eluting with petroleum ether-ethyl acetate mixture $(85: 15)$ to yield $\mathbf{6}$. The NMR data of $\mathbf{6}$ was identical with the previously reported values. ${ }^{11 a}$ To demonstrate the scalability of this reaction, we expanded the scale of the reaction indicated in Table 1, entry 2, to $4 \mathrm{mmol}$ of $\mathrm{N}$ - 
methylindole, using $\mathbf{1 b}(0.62 \mathrm{mmol})$ as catalyst, $0.6 \mathrm{mmol}$ of TFA as co-catalyst, and $8 \mathrm{mmol}$ of (E)-cinnamaldehyde in $8 \mathrm{~mL}$ of $\mathrm{DCM} / \mathrm{iPrOH} 85: 15$ at $0{ }^{\circ} \mathrm{C}$. The desired product 6 (71:29 e.r.) was obtained in $96 \%$ yield $(1.01 \mathrm{~g})$.

General procedure for the derivatization with $(S)$-O-Acetylmandelic acid. To a solution of 6 $(0.1 \mathrm{mmol})$ in $\mathrm{MeOH}(1 \mathrm{~mL})$ at $0{ }^{\circ} \mathrm{C}$ was added $\mathrm{NaBH}_{4}(0.13 \mathrm{mmol})$. The solution was stirred at room temperature for 1 hour, quenched by addition of water $(10 \mathrm{~mL})$ and extracted with AcOEt. The combined organic phase was washed with brine, dried over $\mathrm{MgSO}_{4}$, and the solvent was evaporated under reduced pressure. The crude was dissolved in dry DCM $(1 \mathrm{~mL})$, and then DMAP (0.01 mmol), $(S)$-O-acetylmandelic acid $(0.18 \mathrm{mmol})$ and DCC $(0.18 \mathrm{mmol})$ were added in that order. The mixture was stirred at room temperature for 1 hour under argon. The reaction was diluted with DCM and filtered through Celite. The filtrate was concentrated under reduced pressure and purified by column chromatography on silica gel eluting with petroleum ether-ethyl acetate mixture (90:10) to afford an inseparable mixture of the two diastereoisomeric esters $(\boldsymbol{S}, \boldsymbol{S})-12$ and $(\boldsymbol{R}, \boldsymbol{S})-12$ in near quantitative yields $(0.428-0.439 \mathrm{~g}, 97-99 \%)$.

12: colorless oil; IR (film) $v_{\max }$ 3059, 2930, 2851, 1742, 1672, 1454, 1371, 1232, 1177, 1055, 926, $700 \mathrm{~cm}^{-1}$; ${ }^{1} \mathrm{H}$ NMR $\left(\mathrm{CDCl}_{3}, 300 \mathrm{MHz}\right) \delta$ 7.56-6.92 (m, $\left.28 \mathrm{H}\right), 6.83$ (s, 1H, H-2 of (S,S)-12), 6.72 (s, 1H, H-2 of (R,S)-12), 6.14 (s, 1H, H-14 of (R,S)-12), 5.95 (s, 1H, H-14 of (S,S)-12), 4.19-3.98 (m, 6H), 3.71 (s, 3H, H-1 of $(\boldsymbol{S}, \boldsymbol{S})-\mathbf{1 2}), 3.69$ (s, 3H, H-1 of $(\boldsymbol{R}, \boldsymbol{S})-\mathbf{1 2}), 2.55-2.39$ (m, 1H), 2.32-2.15 (m, 9H); ${ }^{13} \mathrm{C}\left\{{ }^{1} \mathrm{H}\right\} \mathrm{NMR}\left(\mathrm{CDCl}_{3}, 75 \mathrm{MHz}\right) \delta 170.2$ (C), 168.6 (C), 143.7 (C), $137.1(\mathrm{C}), 133.9(\mathrm{C}), 129.2(\mathrm{CH}), 128.7(\mathrm{CH}, 2 \mathrm{C}), 128.3(\mathrm{CH}, 2 \mathrm{C}), 127.6(\mathrm{CH}, 4 \mathrm{C}), 127.0(\mathrm{C})$, $126.1(\mathrm{CH}), 125.8(\mathrm{CH}), 121.5(\mathrm{CH}), 119.3(\mathrm{CH}), 118.6(\mathrm{CH}), 117.4(\mathrm{C}), 109.0(\mathrm{CH}), 74.4(\mathrm{CH})$, $63.9\left(\mathrm{CH}_{2}, \mathrm{C}-12\right.$ of $\left.(\boldsymbol{S}, \mathrm{S})-12\right), 60.3\left(\mathrm{CH}_{2}, \mathrm{C}-12\right.$ of $\left.(\boldsymbol{R}, \boldsymbol{S})-12\right), 38.7(\mathrm{CH}), 34.4\left(\mathrm{CH}_{2}\right), 32.5\left(\mathrm{CH}_{3}\right)$, $20.6\left(\mathrm{CH}_{3}\right)$; HRMS (ESI) $m / z$ : $[\mathrm{M}+\mathrm{H}]^{+}$Calcd for $\mathrm{C}_{28} \mathrm{H}_{28} \mathrm{NO}_{4} 442.2013$; Found 442.2014.

\section{ASSOCIATED CONTENT}

Supporting Information. Copies of ${ }^{1} \mathrm{H}$ and ${ }^{13} \mathrm{C}$ NMR spectra of all compounds, and computational data associated with this paper.

\section{AUTHOR INFORMATION}

\section{Corresponding Author}

*A. M. S. E-mail: sarotti@iquir-conicet.gov.ar 


\section{Author Contributions}

The manuscript was written through contributions of all authors. All authors have given approval to the final version of the manuscript.

\section{Acknowledgements}

This research was supported by UNR (BIO 316, 500 and 504), CONICET (PIP 0660), ANPCyT (PICT-2016-0116 and PICT-2016-2307), CONICET (PIP 11220130100660CO) and PhosAgro/UNESCO/IUPAC (Green Chemistry for Life Program, project 121). G.G.G. and M.O.M thank CONICET for the award of a fellowship.

\section{References}

1 (a) Enantioselective Organocatalysis; Dalko, P. I., Ed.; Wiley-VCH: Weinheim, 2007. (b) Pellissier, H. Recent Developments in Asymmetric Organocatalysis; The Royal Society of Chemistry: Cambridge, UK, 2010.

2 (a) MacMillan, D. W. C. The advent and development of organocatalysis. Nature. 2008, 455, 304. (b) Erkkila, A.; Majander, I.; Pihko, P. M. Iminium Catalysis. Chem. Rev. 2007, 107, 5416. (c) Mukherjee, S.; Yang, J. W.; Hoffmann, S.; List, B. Asymmetric Enamine Catalysis. Chem. Rev. 2007, 107, 5471. (d) Schreyer, L.; Properzi, R.; List, B. IDPi Catalysis. Angew. Chem. Int. Ed. 2019, 58, 12761. (e) Kim, H.; Gerosa, G.; Aronow, J.; Kasaplar, P.; Ouyang, J.; Lingnau, J. B.; Guerry, P.; Farés, C.; List, B. A multi-substrate screening approach for the identification of a broadly applicable Diels-Alder catalyst. Nature Commun. 2019, 10, 770.

3 a) Ahn, S.; Hong, M.; Sundararajan, M.; Ess, D. H. Design and Optimization of Catalysts Based on Mechanistic Insights Derived from Quantum Chemical Reaction Modeling. Chem. Rev. 2019, 119, 6509. b) Poree, C.; Schoenebeck, F. A Holy Grail in Chemistry: Computational Catalyst Design: Feasible or Fiction?. Acc. Chem. Res. 2017, 50, 605 .

4 a) Cheong, P. H-Y.; Legault, C. Y.; Um, J. M.; Çelebi-Ölçüm, N.; Houk, K. N. Quantum Mechanical Investigations of Organocatalysis: Mechanisms, Reactivities, 
and Selectivities. Chem. Rev. 2011, 111, 5042. For recent leading references, see: b) Lam, Y.; Grayson, M. N.; Holland, M. C., Simon, A.; Houk, K. N. Theory and Modeling of Asymmetric Catalytic Reactions. Acc. Chem. Res. 2016, 49, 750. c) Lu, T.; Zhu, R.; An, Y.; Wheeler, S. E. Origin of Enantioselectivity in the Propargylation of Aromatic Aldehydes Catalyzed by Helical N-Oxides. J. Am. Chem. Soc. 2012, 134, 3095. d) Lam, Y.-H.; Houk, K. N. Origins of Stereoselectivity in Intramolecular Aldol Reactions Catalyzed by Cinchona Amines. J. Am. Chem. Soc. 2015, 137, 2116. e) Reid, J. P.; Goodman, J. M. Goldilocks Catalysts: Computational Insights into the Role of the 3,3' Substituents on the Selectivity of BINOL-Derived Phosphoric Acid Catalysts. J. Am. Chem. Soc. 2016, 138, 7910.

5 (a) Kozlowski, M. C.; Dixon, S. L.; Panda, M; Lauri, G. Quantum Mechanical Models Correlating Structure with Selectivity: Predicting the Enantioselectivity of $\beta$-Amino Alcohol Catalysts in Aldehyde Alkylation. J. Am. Chem. Soc. 2003, 125, 6614. b) Ianni, J. C.; Annamalai, V.; Phuan, P.-W.; Panda, M.; Kozlowski, M. C. A Priori Theoretical Prediction of Selectivity in Asymmetric Catalysis: Design of Chiral Catalysts by Using Quantum Molecular Interaction Fields. Angew. Chem. Int. Ed. 2006, 45, 5502. c) Denmark, S. E.; Gould, N. D.; Wolf, L. M. A Systematic Investigation of Quaternary Ammonium Ions as Asymmetric Phase-Transfer Catalysts. Application of Quantitative Structure Activity/Selectivity Relationships. J. Org. Chem. 2011, 76, 4337. d) Sigman, M. S.; Harper, K. C.; Bess, E. N.; Milo, A. The Development of Multidimensional Analysis Tools for Asymmetric Catalysis and Beyond. Acc. Chem. Res. 2016, 49, 1292. e) Reid, J. P.; Sigman, M. S. Holistic prediction of enantioselectivity in asymmetric catalysis. Nature. 2019, 571, 343.

6 (a) Doney, A. C.; Rooks, B. J.; Lu, T.; Wheeler, S. E. Design of Organocatalysts for Asymmetric Propargylations through Computational Screening. ACS Catal. 2016, 6, 7948. (b) Guan, Y.; Ingman, V. M.; Rooks, B. J.; Wheeler, S. E. AARON: An Automated Reaction Optimizer for New Catalysts. J. Chem. Theory Comput. 2018, 14, 5249.

7 (a) Odagi, M.; Furukori, K.; Yamamoto, Y.; Sato, M.; Lida, K.; Yamanaka, M.; Nagasawa, K. Origin of Stereocontrol in Guanidine-Bisurea Bifunctional Organocatalyst That Promotes $\alpha$-Hydroxylation of Tetralone-Derived $\beta$-Ketoesters: 
Asymmetric Synthesis of $\beta$ - and $\gamma$-Substituted Tetralone Derivatives via Organocatalytic Oxidative Kinetic Resolution. J. Am. Chem. Soc. 2015, 137, 1909. (b) Fleming, E. M.; Quigley, C.; Rozas, I.; Connor, S. J. Computational Study-Led Organocatalyst Design: A Novel, Highly Active Urea-Based Catalyst for Addition Reactions to Epoxides. J. Org. Chem. 2008, 73, 948. (c) Mitsumori, S.; Zhang, H.; Cheong, P. H-Y.; Houk, K. N.; Tanaka, F.; Barbas, C. F., III. Direct Asymmetric antiMannich-Type Reactions Catalyzed by a Designed Amino Acid. J. Am. Chem. Soc. 2006, 128, 1040. (d) Pan, L.; Ding, X.; Ding, J.; Li, D.; Chen, J.; Zuo, X.; An, R. Design and Synthesis of L-Proline Derivatives as Enantioselective Organocatalysts for Synthesis of the (S)-Wieland-Miescher Ketone. ChemistrySelect. 2017, 2, 11999.

8 a) Comba, M. B.; Tsai, Y.; Sarotti, A. M.; Mangione, M. I.; Suárez, A. G.; Spanevello, R. A. Levoglucosenone and Its New Applications: Valorization of Cellulose Residues. Eur. J. Org. Chem. 2018, 5, 590. b) Corne, V.; Botta, M. C.; Giordano, E. D. V.; Giri, G. F.; Llompart, D. F.; Biava, H. D.; Sarotti, A. M.; Mangione, M. I.; Mata, E. G.; Suárez, A. G.; Spanevello, R. A. Cellulose recycling as a source of raw chirality. Pure Appl. Chem. 2013, 8, 85.

9 Gerosa, G. G.; Spanevello, R. A.; Suárez, A. G.; Sarotti, A. M. Joint Experimental, in Silico, and NMR Studies toward the Rational Design of Iminium-Based Organocatalyst Derived from Renewable Sources. J. Org. Chem. 2015, 80, 7626.

10 a) Terrasson, V.; de Figueiredo, R. M.; Campagne, J. M. Organocatalyzed Asymmetric Friedel-Crafts Reactions. Eur. J. Org. Chem. 2010, 2635. b) Bartoli, G.; Bencivenni, G.; Dalpozzo, R. Organocatalytic strategies for the asymmetric functionalization of indoles. Chem. Soc. Rev. 2010, 39, 4449.

11 (a) Austin, J. F.; MacMillan, D. W. C. Enantioselective Organocatalytic Indole Alkylations. Design of a New and Highly Effective Chiral Amine for Iminium Catalysis. J. Am. Chem. Soc. 2002, 124, 1172. b) Holland, M. C.; Metternich, J. B.; Daniliuc, C.; Schweizer, W. B.; Gilmour, R. Aromatic Interactions in Organocatalyst Design: Augmenting Selectivity Reversal in Iminium Ion Activation. Chem. Eur. J. 2015, 21, 10031. c) Grošelj, U.; Podlipnik, Č.; Bezenšek, J.; Svete, J.; Stanovnik, B. Reversal of the Stereochemical Course of 1-Methyl-1H-indole Addition to 
Cinnamaldehyde with cis-5-Benzyl-(2-fluoromethyl)-2,3-dimethylimidazolidin-4-ones as Catalysts - a Puzzling 'Fluorine Effect'. Helv. Chim. Acta. 2013, 96, 1815.

12 (a) Sarotti, A. M.; Spanevello, R. A.; Suárez, A. G.; Echeverría, G. A.; Piro, O. E. 1,3Dipolar Cycloaddition Reactions of Azomethine Ylides with a Cellulose-Derived Chiral Enone. A Novel Route for Organocatalysts Development. Org. Lett. 2012, 14, 2556. (b) Gerosa, G. G.; Grimblat, N.; Spanevello, R. A.; Suárez, A. G.; Sarotti, A. M. Mechanistic insight into the acid-catalyzed isomerization of biomass-derived polysubstituted pyrrolidines: an experimental and DFT study. Org. Biomol. Chem. 2017, 15, 426.

13 Seco, J. M.; Quiñoá, E.; Riguera, R. The Assignment of Absolute Configuration by NMR. Chem. Rev. 2004, 104, 17.

14 Pisano, P. L.; Sarotti, A. M.; Pellegrinet, S. C. An experimental/theoretical approach to determine the optical purity and the absolute configuration of endo- and exo-norborn5-en-2-ol using mandelate derivatives. Tetrahedron Lett. 2009, 50, 6121.

15 In Ref. 9 the face topicity analysis was carried out considering the $\mathrm{C} \alpha$ of the iminium ion. In this work we kept this rule to simplify the discussion, despite $\mathrm{C} \alpha$ does not react with the nucleophile in FC reactions.

16 Bartók, M. Unexpected Inversions in Asymmetric Reactions: Reactions with Chiral Metal Complexes, Chiral Organocatalysts, and Heterogeneous Chiral Catalysts. Chem. Rev. 2010, 110, 1663.

17 (a) Simón, L.; Goodman, J. M. DFT Study on the Factors Determining the Enantioselectivity of Friedel-Crafts Reactions of Indole with N-Acyl and NTosylimines Catalyzed by BINOL-Phosphoric Acid Derivatives. J. Org. Chem. 2010, 75, 589. (b) Hirata, T.; Yamanaka, M. DFT Study of Chiral-Phosphoric-Acid-Catalyzed Enantioselective Friedel-Crafts Reaction of Indole with Nitroalkene: Bifunctionality and Substituent Effect of Phosphoric Acid. Chem. Asian J. 2011, 6, 510.

18 (a) Dapprich, S.; Komáromi, I.; Byun, K. S.; Morokuma, K.; Frisch, M. J. A new ONIOM implementation in Gaussian98. Part I. The calculation of energies, gradients, vibrational frequencies and electric field derivatives. Journal of Molecular Structure (Theochem). 1999, 461, 1. (b) Vreven, T.; Morokuma, K. On the application of the 
IMOMO (integrated molecular orbital + molecular orbital) method. J. Comput. Chem. 2000, 21, 1419.

19 Chung, L. W.; Sameera, W. M. C.; Ramozzi, R.; Page, A. J.; Hatanaka, M.; Petrova, G. P.; Harris, T. V.; Li, X.; Ke, Z.; Liu, F.; Li, H. -B.; Ding, L.; Morokuma, K. The ONIOM Method and Its Applications. Chem. Rev. 2015, 115, 5678.

20 Nishio, M. The $\mathrm{CH} / \pi$ hydrogen bond in chemistry. Conformation, supramolecules, optical resolution and interactions involving carbohydrates. Phys. Chem. Chem. Phys. 2011, 13, 13873.

21 a) Distance between the centroid of the phenyl group at C-7 and the closest hydrogen atom of the $\mathrm{N}_{-} \mathrm{CH}_{3}$ group in 5. b) Distance between the centroid of the six membered ring in 5 and the closest hydrogen atom of the $\mathrm{CH}_{3}$ group at $\mathrm{C}-8$.

22 Krenske, E. H.; Houk, K. N. Aromatic Interactions as Control Elements in Stereoselective Organic Reactions. Acc. Chem. Res. 2013, 46, 979.

23 Yanai, T.; Tew, D. P.; Handy, N. C. A new hybrid exchange-correlation functional using the Coulomb-attenuating method (CAM-B3LYP). Chem. Phys. Lett. 2004, 393, 51.

24 Mohan, N.; Vijayalakshmi, K. P.; Koga, N.; Suresh, C. H. Comparison of aromatic $\mathrm{NH} \cdots \pi, \mathrm{OH}^{\cdots} \pi$, and $\mathrm{CH} \cdots \pi$ interactions of alanine using MP2, CCSD, and DFT methods. J. Comput. Chem. 2010, 31, 2874.

25 a) Neel, A. J.; Hilton, M. J.; Sigman, M. S.; Toste, F. D. Exploiting non-covalent $\pi$ interactions for catalyst design. Nature. 2017, 543, 637. b) Wheeler, S. E.; Seguin, T. J.; Guan, Y.; Doney, A. C. Noncovalent Interactions in Organocatalysis and the Prospect of Computational Catalyst Design. Acc. Chem. Res. 2016, 49, 1061. c) Seguin, T. J.; Lu, T.; Wheeler, S. E. Enantioselectivity in Catalytic Asymmetric Fischer Indolizations Hinges on the Competition of $\pi$-Stacking and $\mathrm{CH} / \pi$ Interactions. Org. Lett. 2015, 17, 3066.

26 Sarotti, A. M.; Spanevello, R. A.; Suárez, A. G. An efficient microwave-assisted green transformation of cellulose into levoglucosenone. Advantages of the use of an experimental design approach. Green Chem. 2007, 9, 1137. 
27 Cabrera, S.; Gomez Arrayás, R.; Martín-Matute, B.; Cossío, F.; Carretero, J. C. CuIFesulphos complexes: efficient chiral catalysts for asymmetric 1,3-dipolar cycloaddition of azomethine ylides. Tetrahedron. 2007, 63, 6587.

28 White, B. D.; Mallen, J.; Arnold, K. A.; Fronczek, F. R.; Gandour, R. D.; Gehrig, L. M. B.; Gokel, G. W. Peptide side-arm derivatives of lariat ethers and bibracchial lariat ethers: syntheses, cation binding properties, and solid state structural data. J. Org. Chem. 1989, 54, 937. 